\title{
Ru(II)- and Os(II)-Induced Cycloisomerization of Phenol- Tethered Alkyne for Functional Chromene and Chromone
}

\section{Complexes}

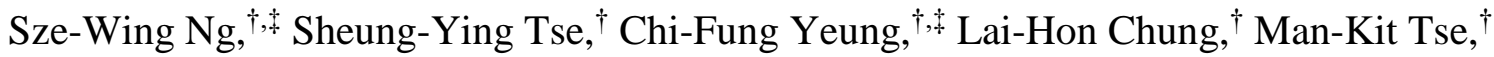
Shek-Man Yiu, ${ }^{\dagger}$ and Chun-Yuen Wong*t,

†Department of Chemistry, City University of Hong Kong, Tat Chee Avenue, Kowloon, Hong Kong SAR

*State Key Laboratory of Terahertz and Millimeter Waves, City University of Hong Kong, Tat Chee Avenue, Kowloon, Hong Kong SAR

E-mail: acywong@cityu.edu.hk

\section{Table of Contents}

Page

X-Ray Crystallography

S2

Variable Temperature ${ }^{31}$ P NMR Spectroscopy of $\mathbf{R u}-\mathbf{C l}-\mathbf{o n e}$

S3

Free Radical Scavenging Activity by DPPH Assay

S4

Computational Methodology S5

NMR Spectra for All the Complexes S6

References $\mathrm{S} 75$ 


\section{X-ray Crystallography}
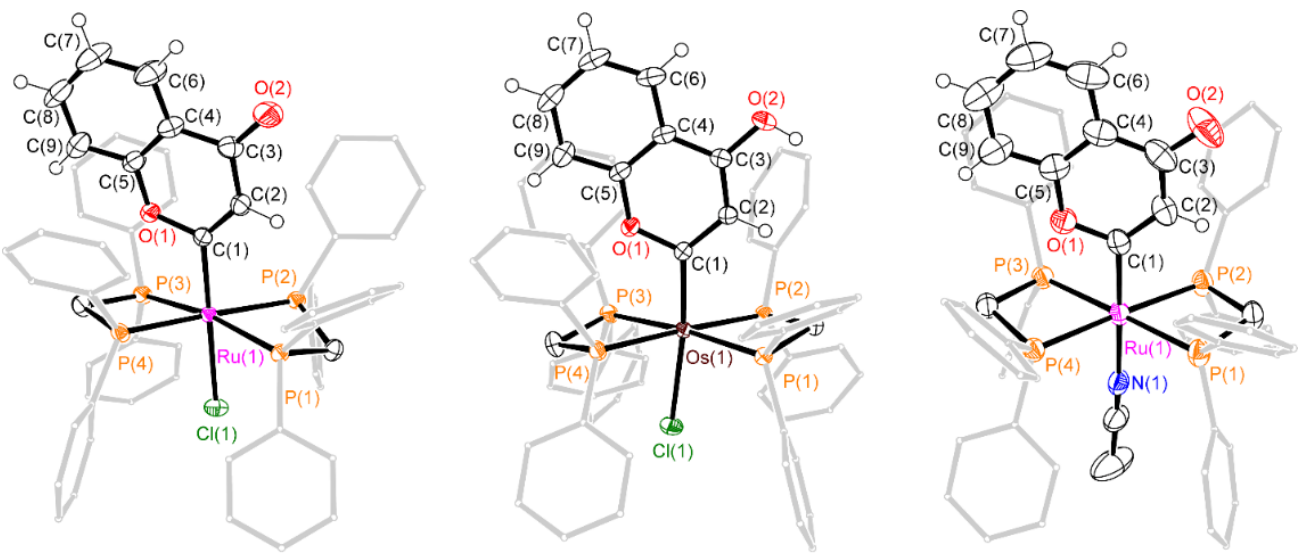

Figure S1. Perspective views of $\mathbf{R u}-\mathbf{C l}-0$ ene, $\mathrm{Os}-\mathbf{C l}-\mathbf{e n e}$ and $\mathbf{R u}-\mathbf{C H}_{3} \mathbf{C N}-$ one (from left to right) as represented by $50 \%$ probability ellipsoids (phenyl rings on dppm are represented by gray sticks for clarity). 


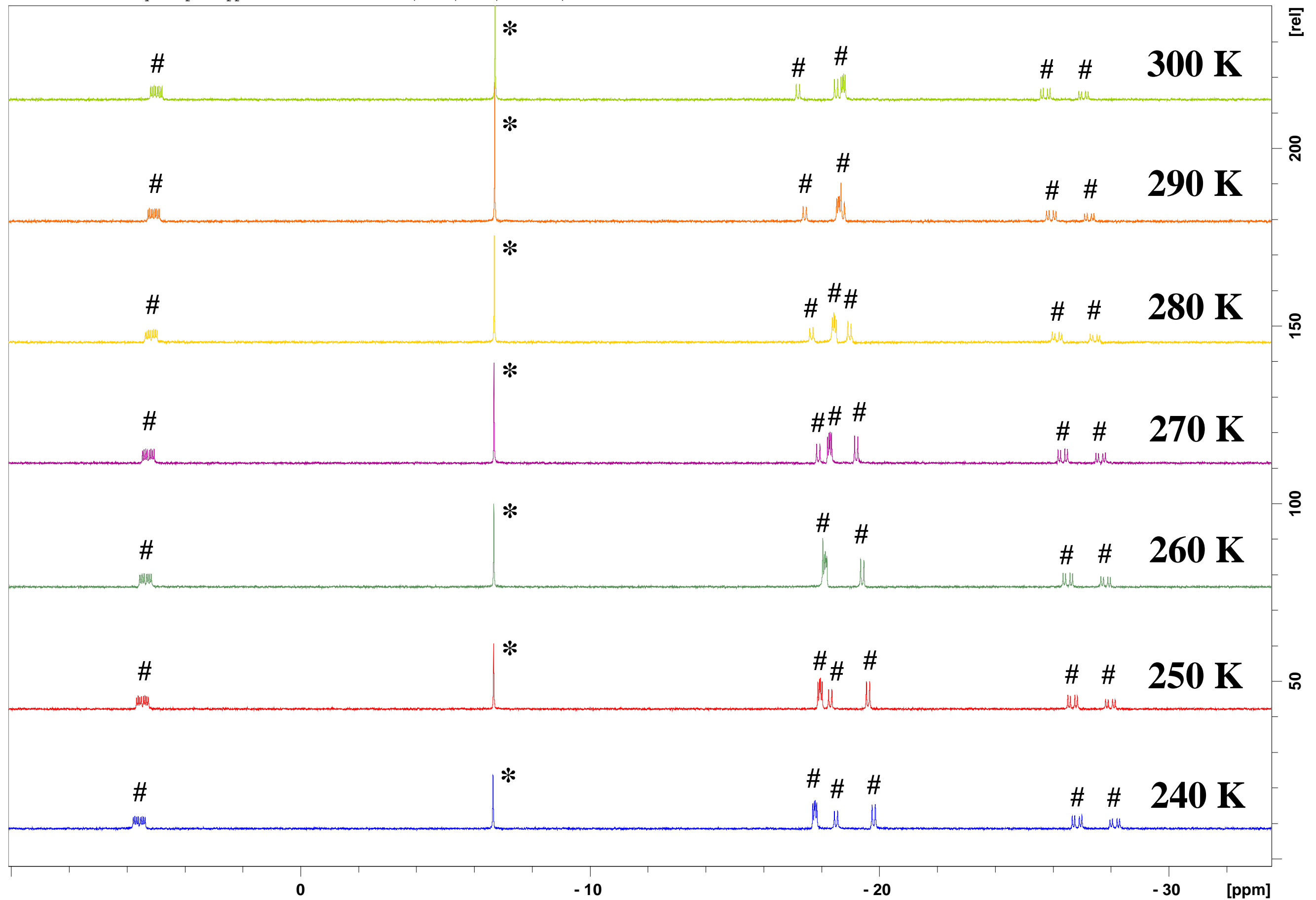

Figure S2. The ${ }^{31} \mathrm{P}\left\{{ }^{1} \mathrm{H}\right\}$ NMR spectra of $\mathbf{R u} \mathbf{C l}$ one in $\mathrm{CD}_{2} \mathrm{Cl}_{2}$ at different temperatures $(*=$ trans isomer, \# $=$ cis isomer). 
Free Radical Scavenging Activity by DPPH Assay

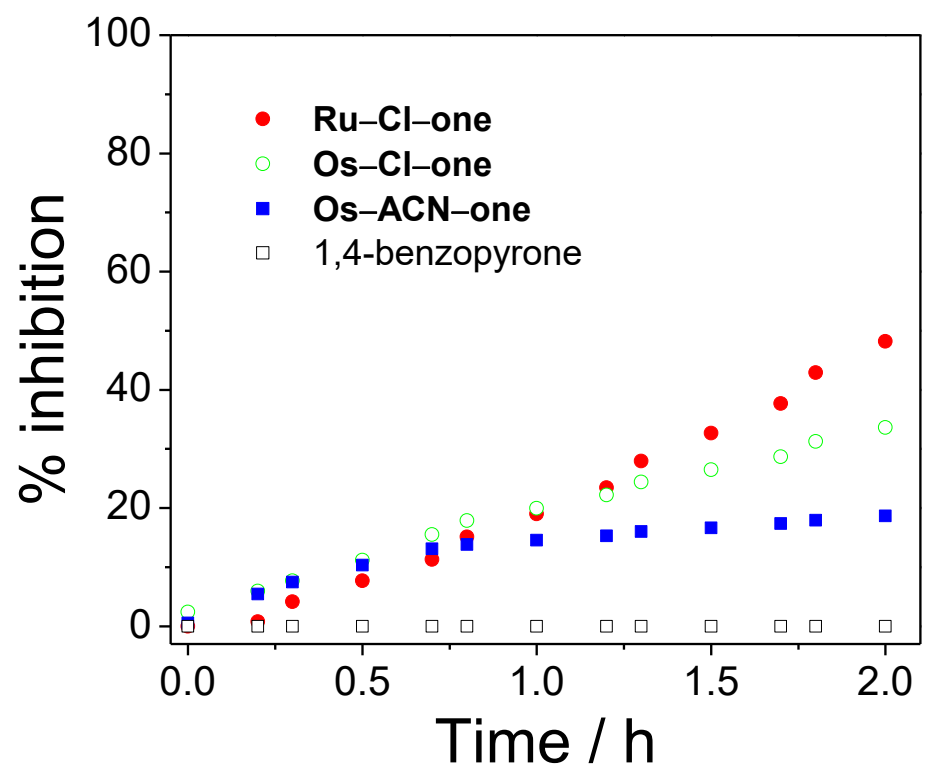

Figure S3. Scavenging of DPPH radical by 1,4-benzopyrone, Ru-Cl-one, Os-Cl-one and Os-ACN-one (OTf as counterion) $(0.35 \mathrm{mM})$. 


\section{Computational Methodology}

The relative energies of $\mathbf{M}-\mathbf{C l}-\mathbf{e n e}$ and $\mathbf{M}-\mathbf{C l}-\mathbf{o n e}$ were calculated by Density Functional Theory (DFT) calculations using the ORCA software package (version 4.1.1). ${ }^{1}$ All the calculated structures were optimized in the gas phase at the BP86/def2-SVP level with the Grimme's DFTD3 method to account for the dispersion effects, and the Resolution of Identity (RI) approximation to speed up the calculations. Tight SCF convergence criteria were used throughout.

The energies used for comparsions were obtained from single-point calculations on the BP86 optimized geometries using the hybrid PBE0 functional with the conductor-like polarizable continuum model $\left(\mathrm{CPCM}\right.$; solvent $\left.=\mathrm{CH}_{2} \mathrm{Cl}_{2}\right)$ to account for solvent effect, and the Grimme's DFT-D3 method for dispersion correction. The combination of RI and the "chain of spheres exchange" algorithms (RIJCOSX) was used to speed up the calculations. 


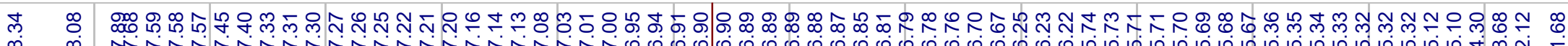

। 1 |

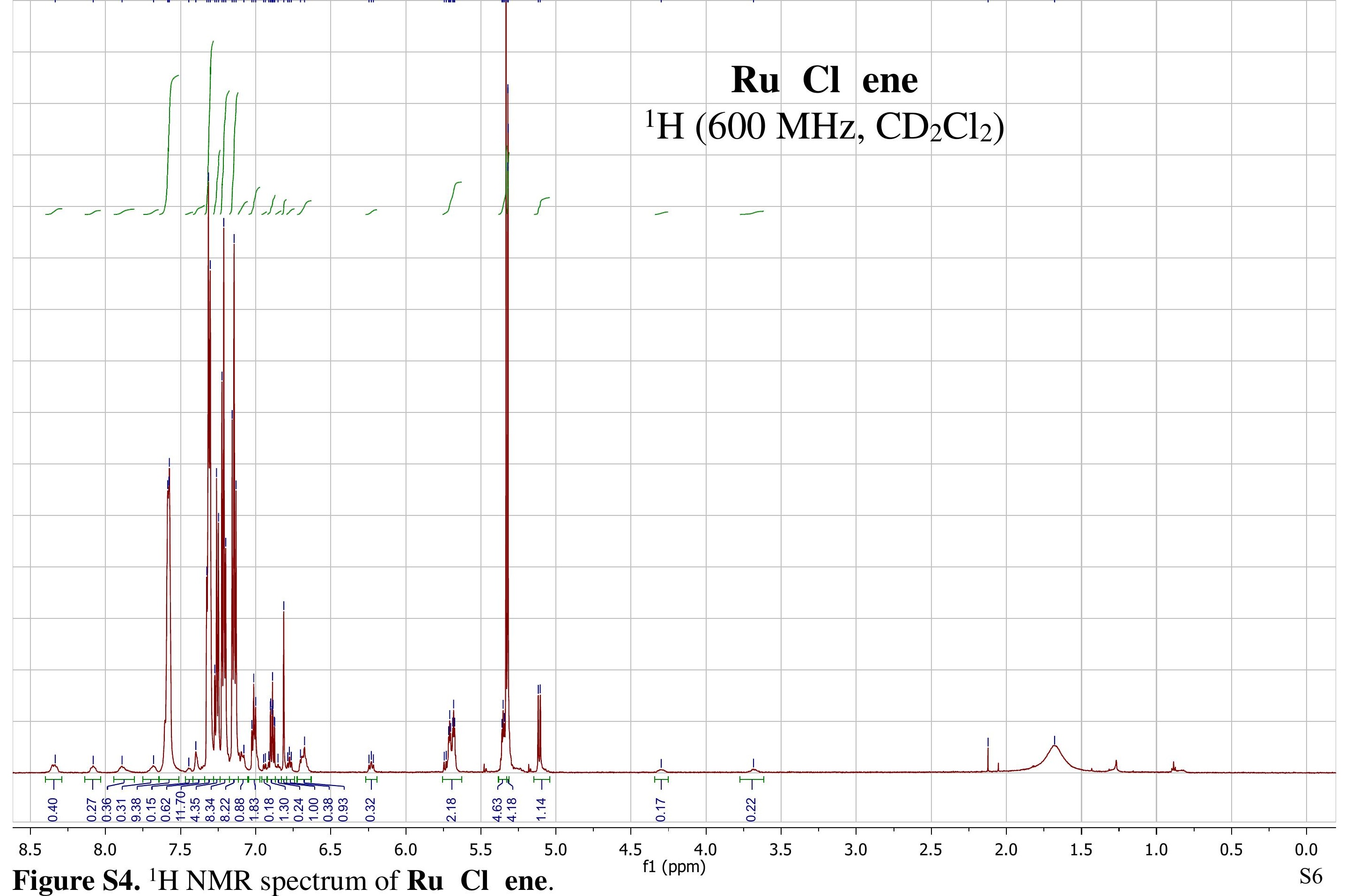




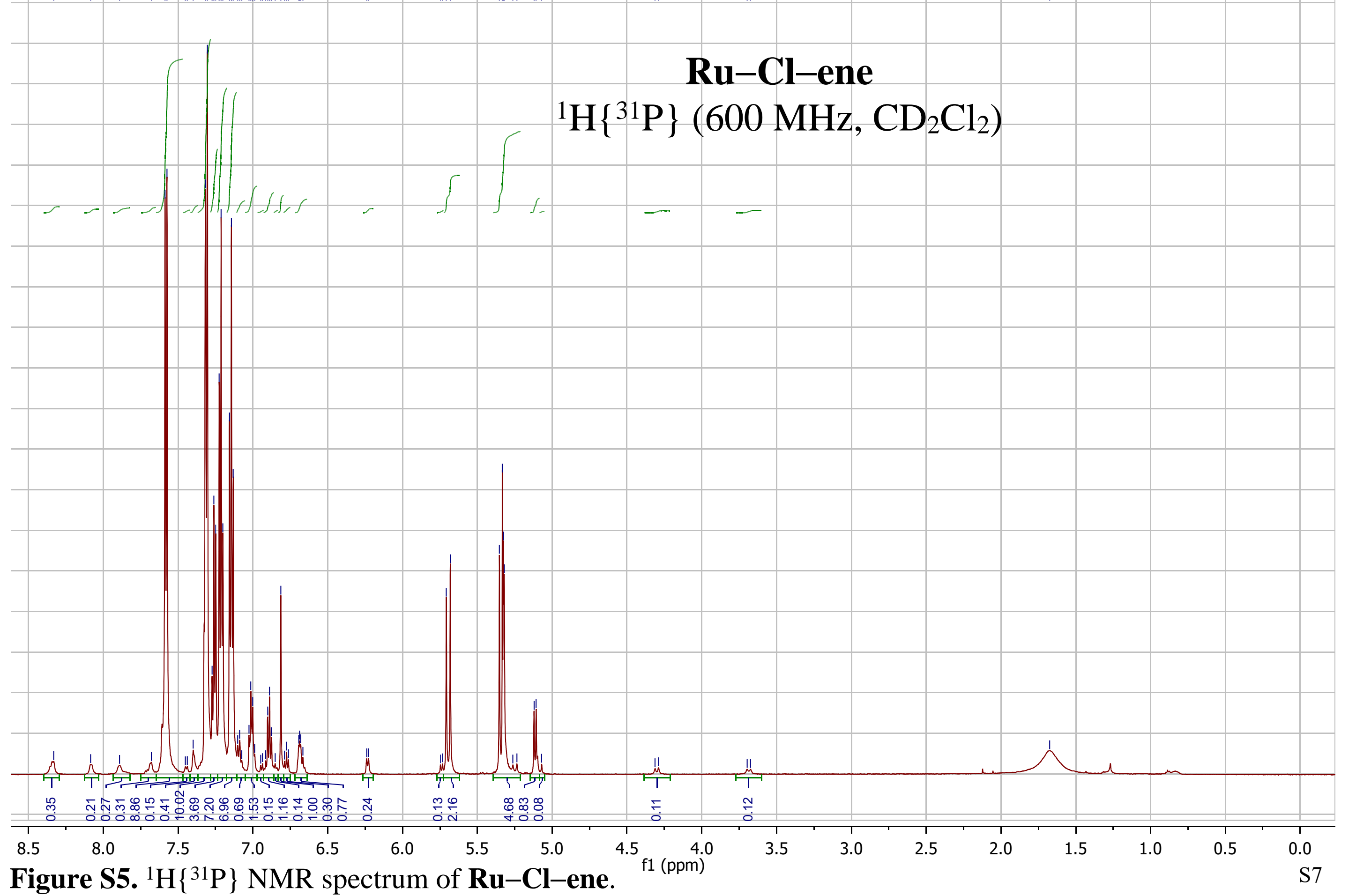




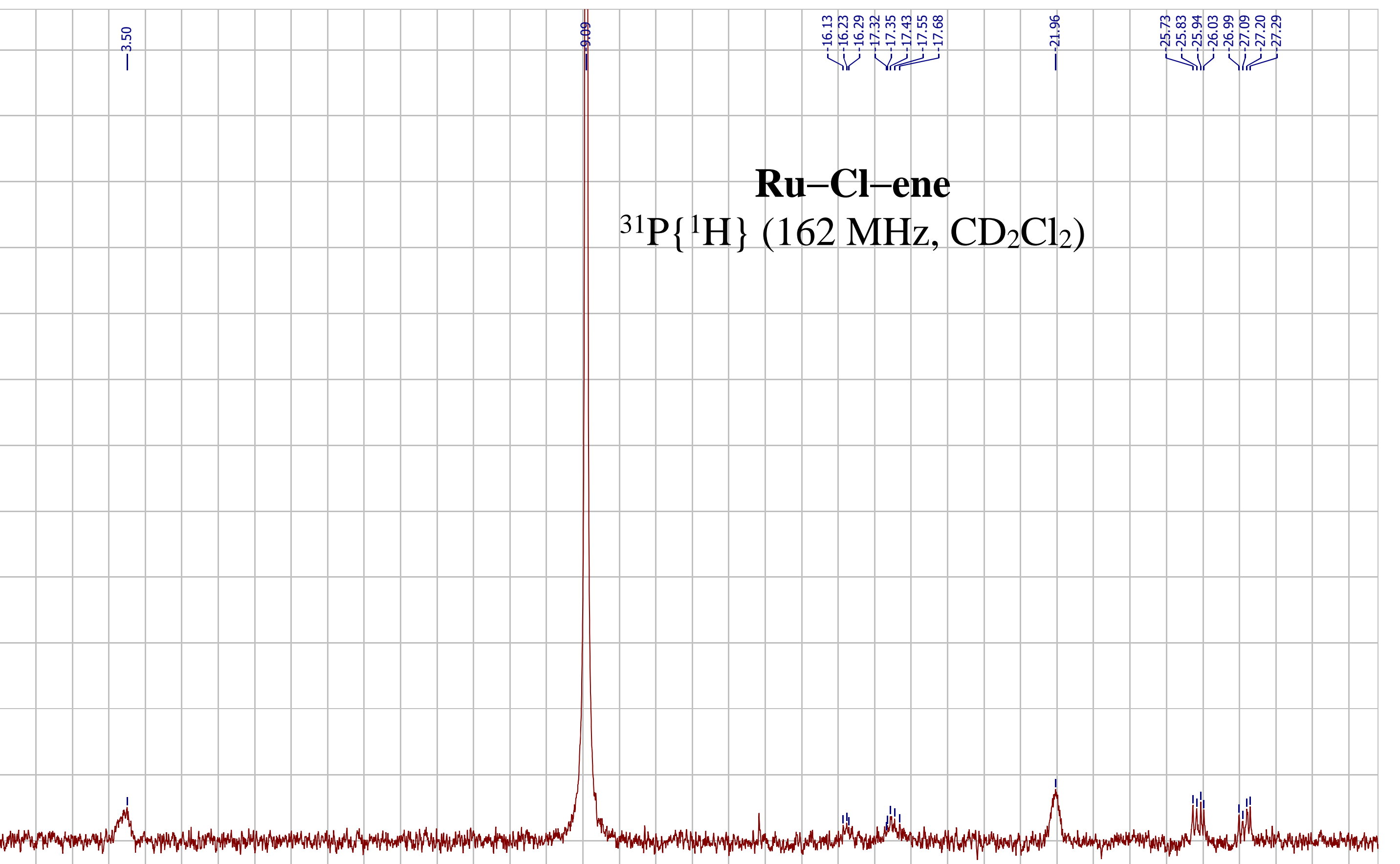




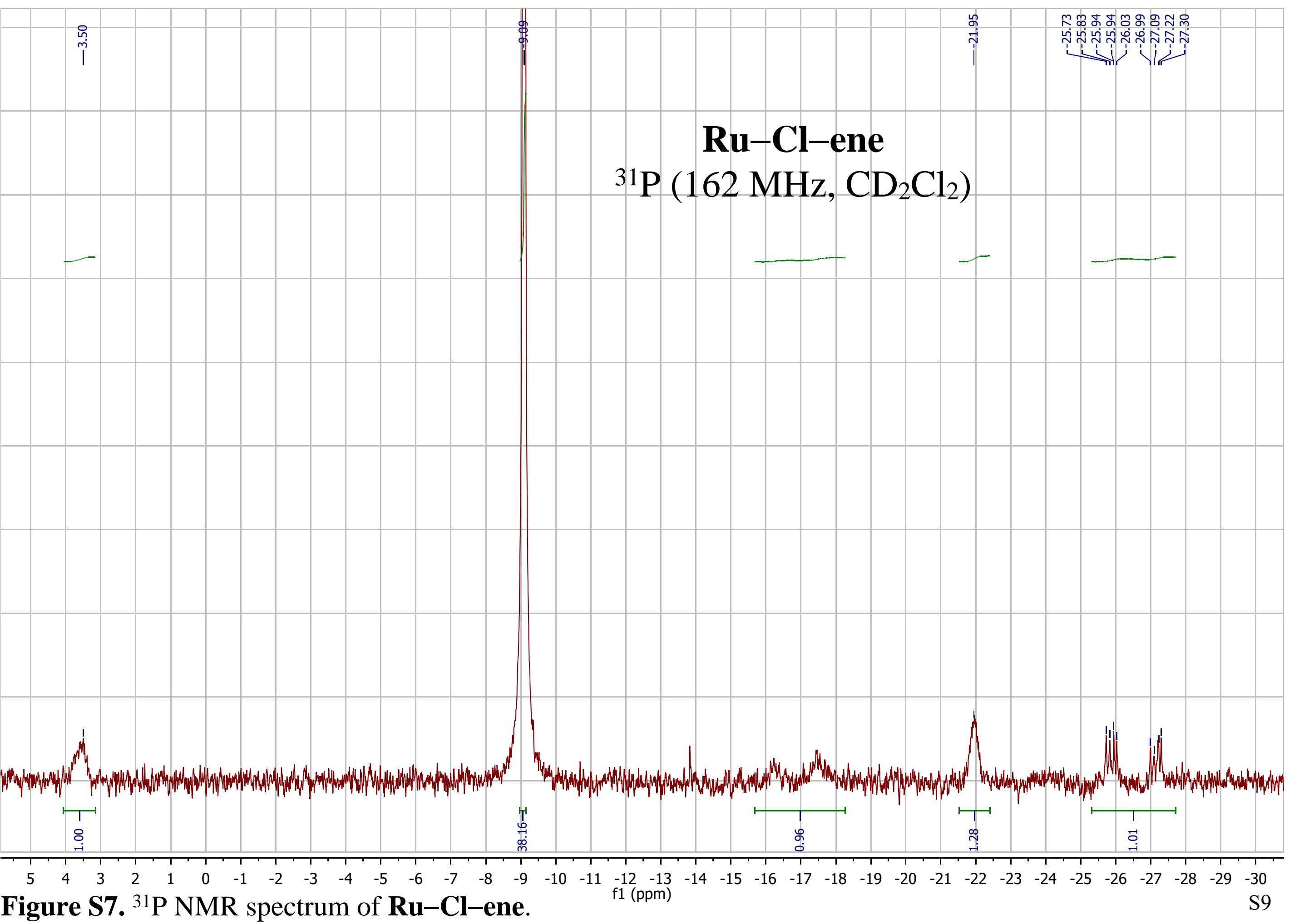




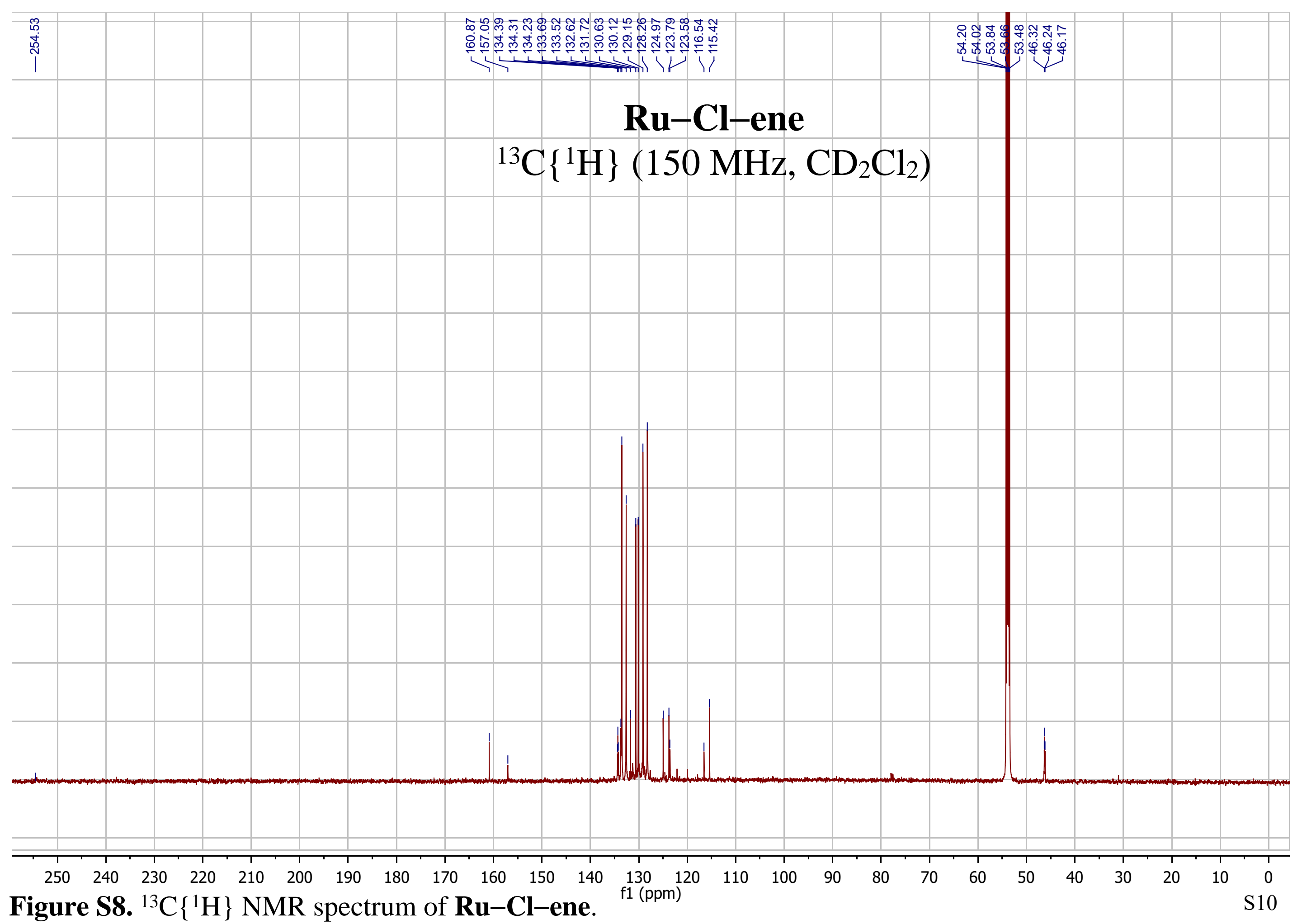




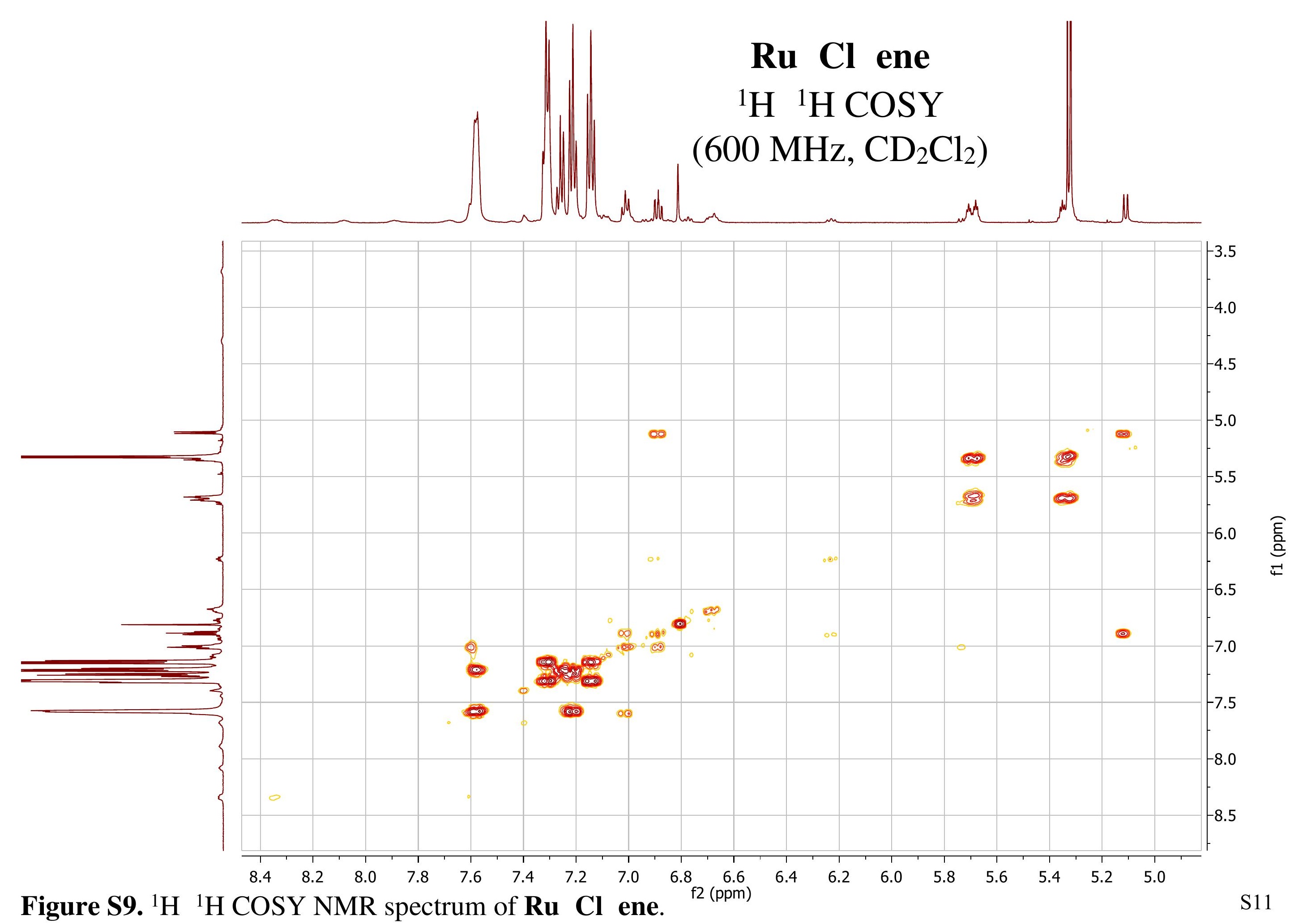




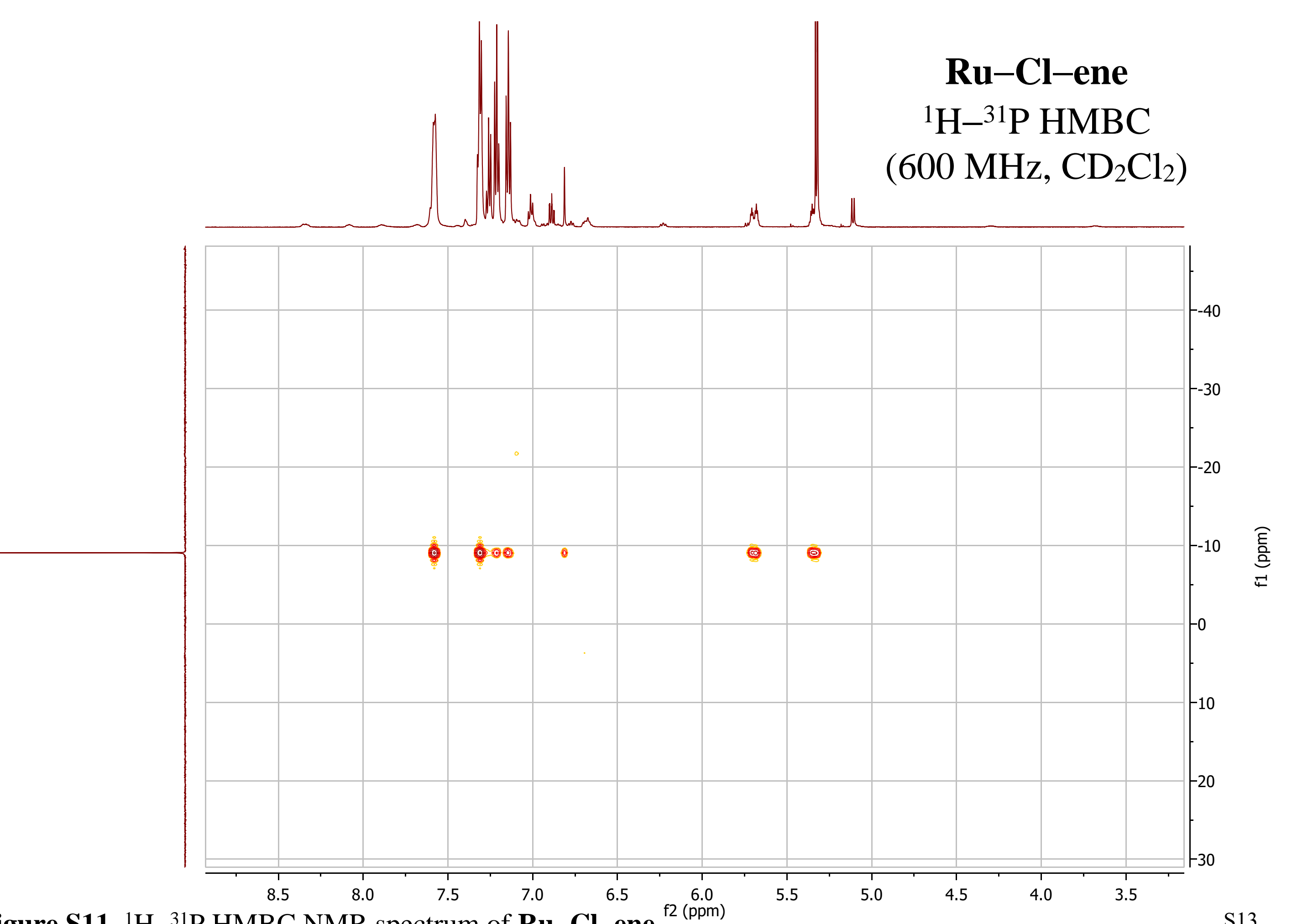

Figure S11. ${ }^{1} \mathrm{H} \quad{ }^{31} \mathrm{P}$ HMBC NMR spectrum of Ru Cl ene. 


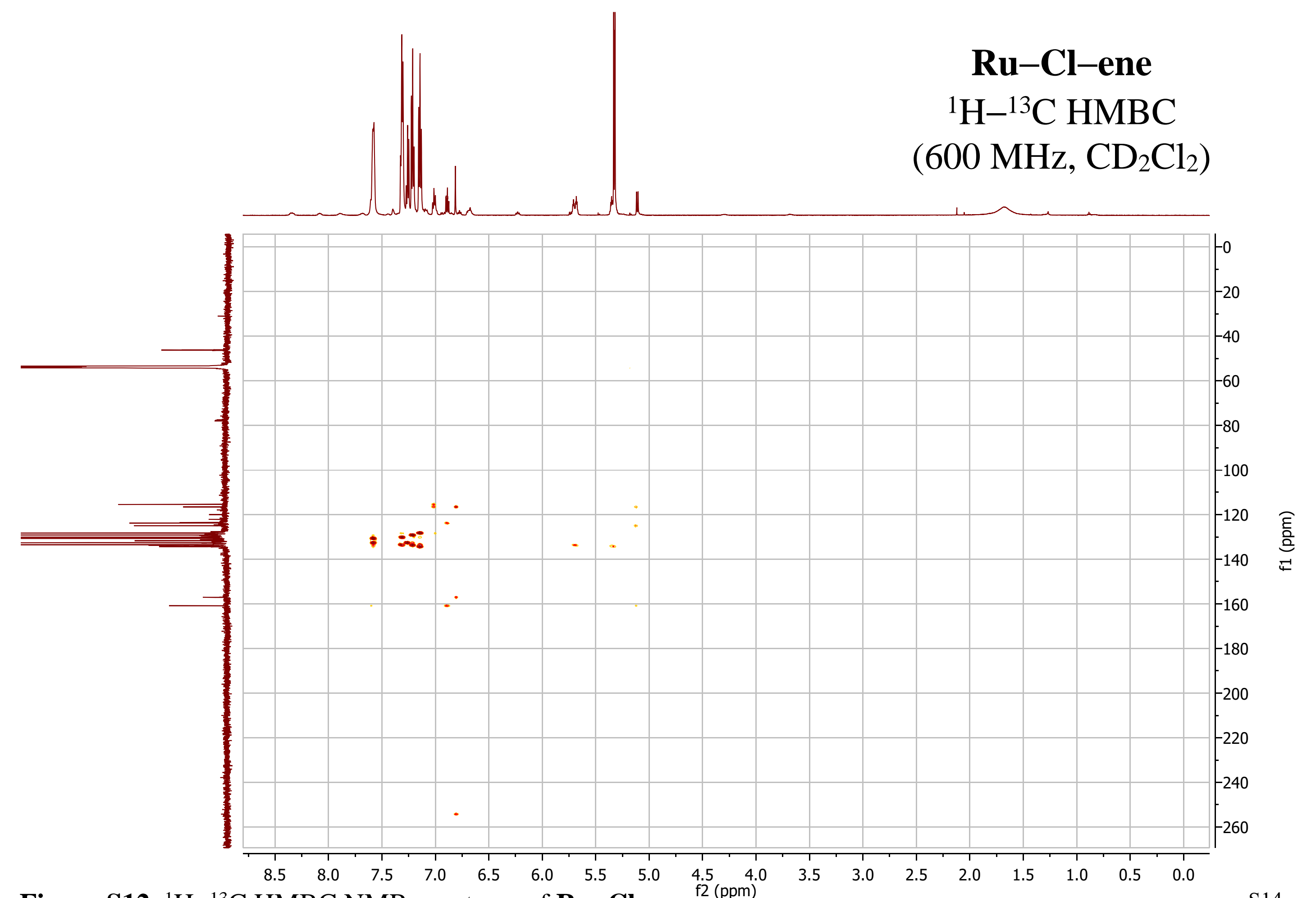

Figure S12. ${ }^{1} \mathrm{H} \quad{ }^{13} \mathrm{C}$ HMBC NMR spectrum of Ru Cl ene. ${ }^{\mathrm{f} 2(\mathrm{ppm})}$ 


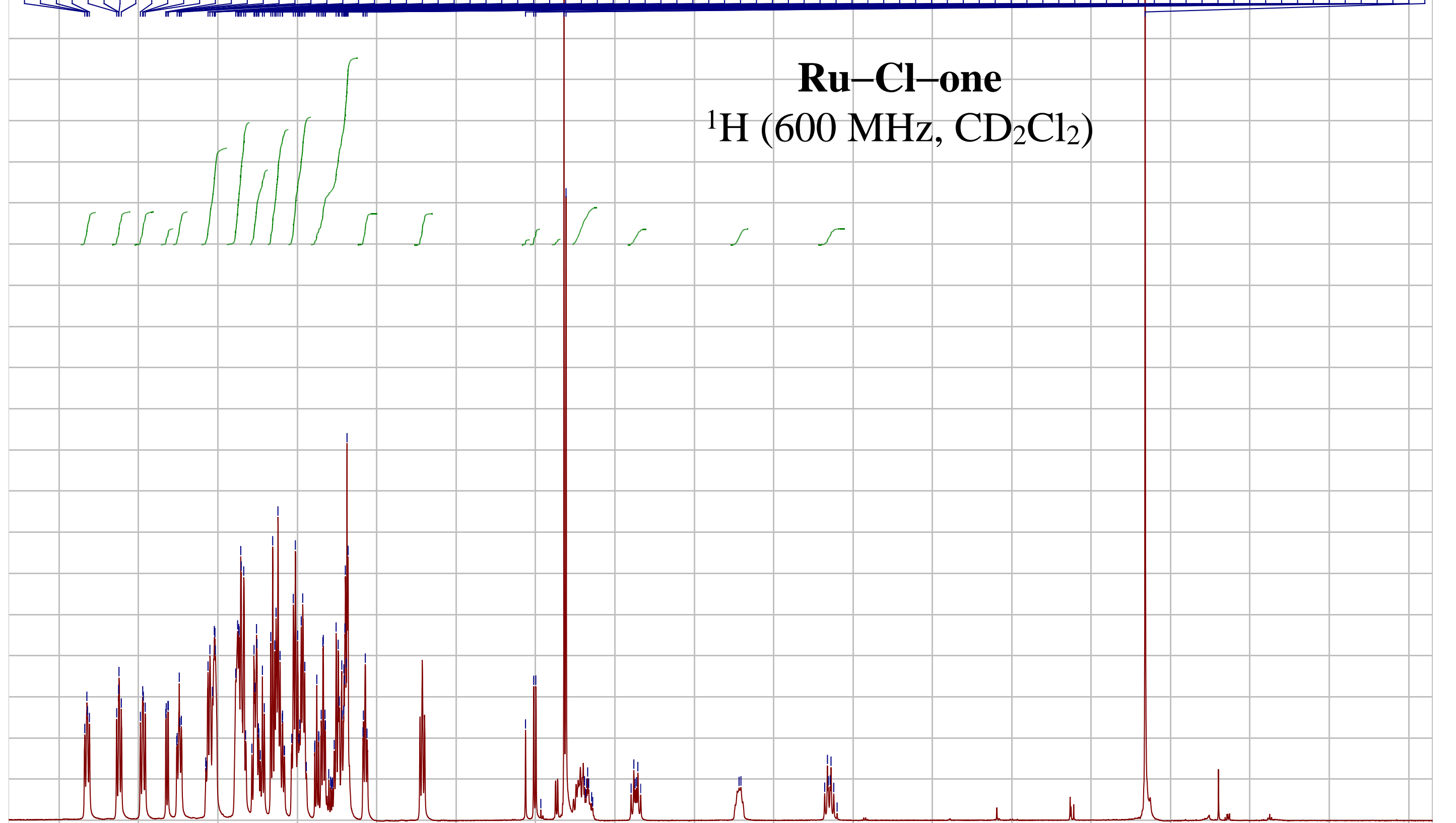

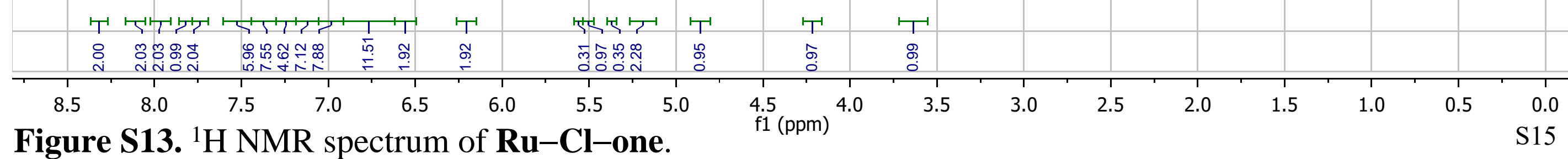



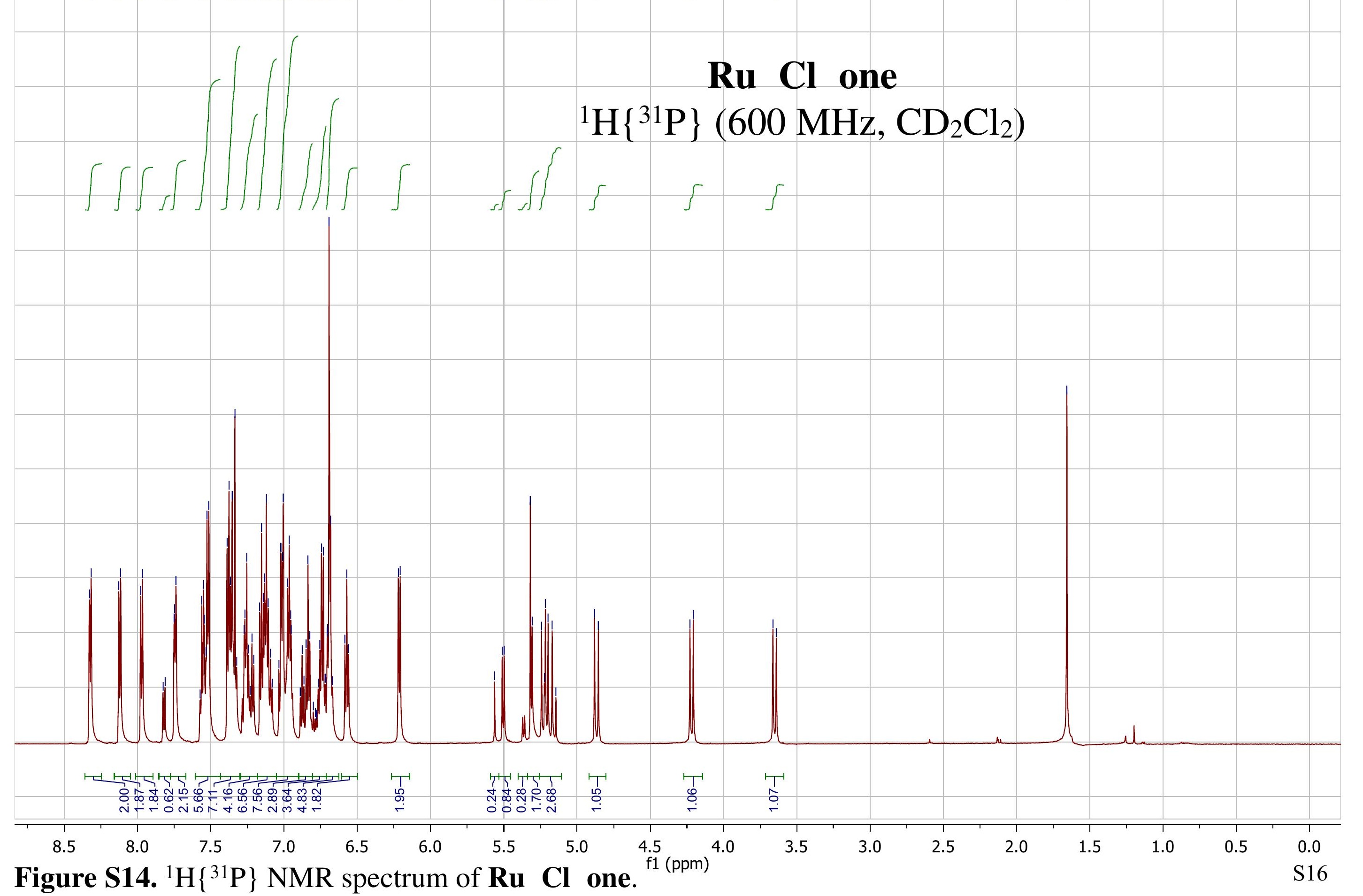


\section{Ru Cl one \\ ${ }^{31} \mathrm{P}\left\{{ }^{1} \mathrm{H}\right\}\left(162 \mathrm{MHz}, \mathrm{CD}_{2} \mathrm{Cl}_{2}\right)$}

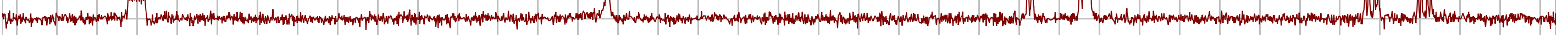

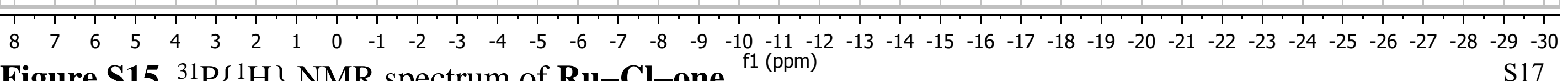

Figure S15. ${ }^{31} \mathrm{P}\left\{{ }^{1} \mathrm{H}\right\}$ NMR spectrum of Ru Cl one. 


\section{Ru Cl one}

\section{${ }^{31} \mathrm{P}\left(162 \mathrm{MHz}, \mathrm{CD}_{2} \mathrm{Cl}_{2}\right)$}
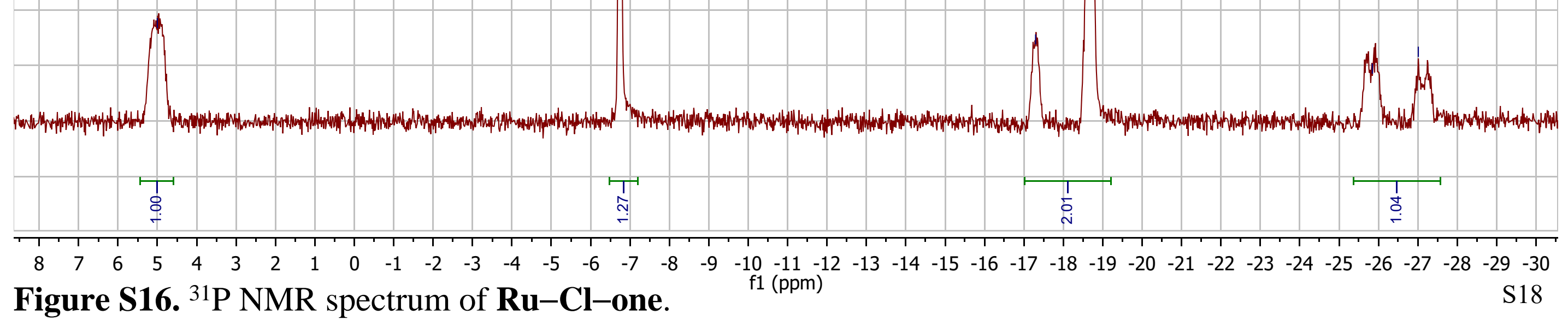


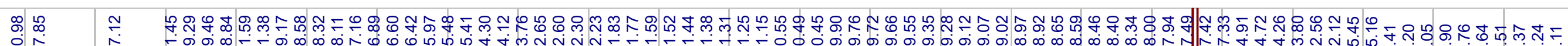

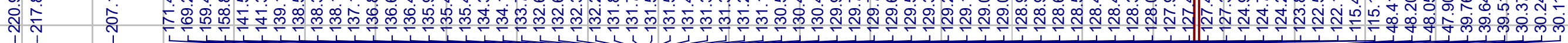






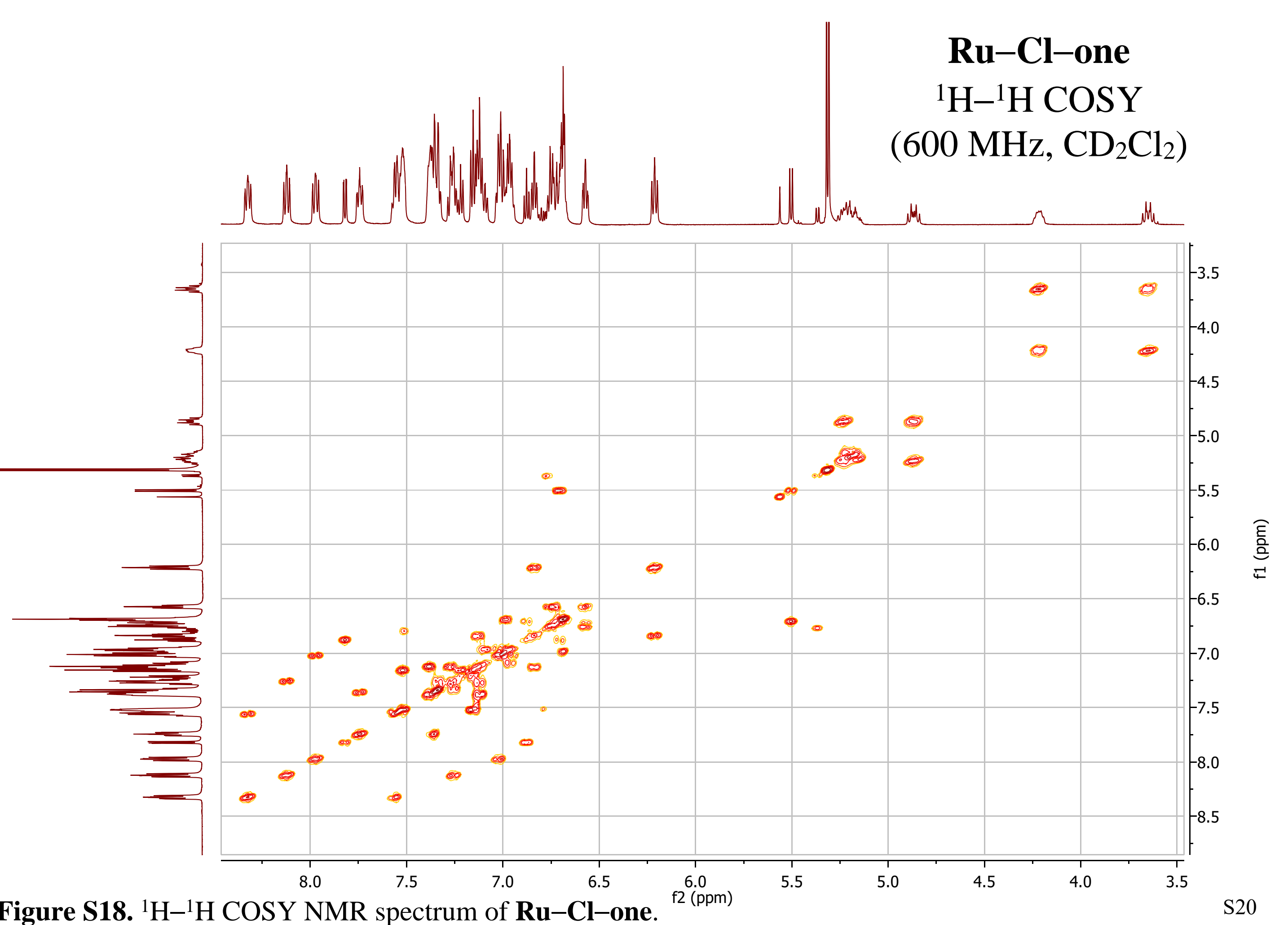

Figure S18. ${ }^{1} \mathrm{H} \quad{ }^{1} \mathrm{H}$ COSY NMR spectrum of Ru $\mathbf{C l}$ one. 


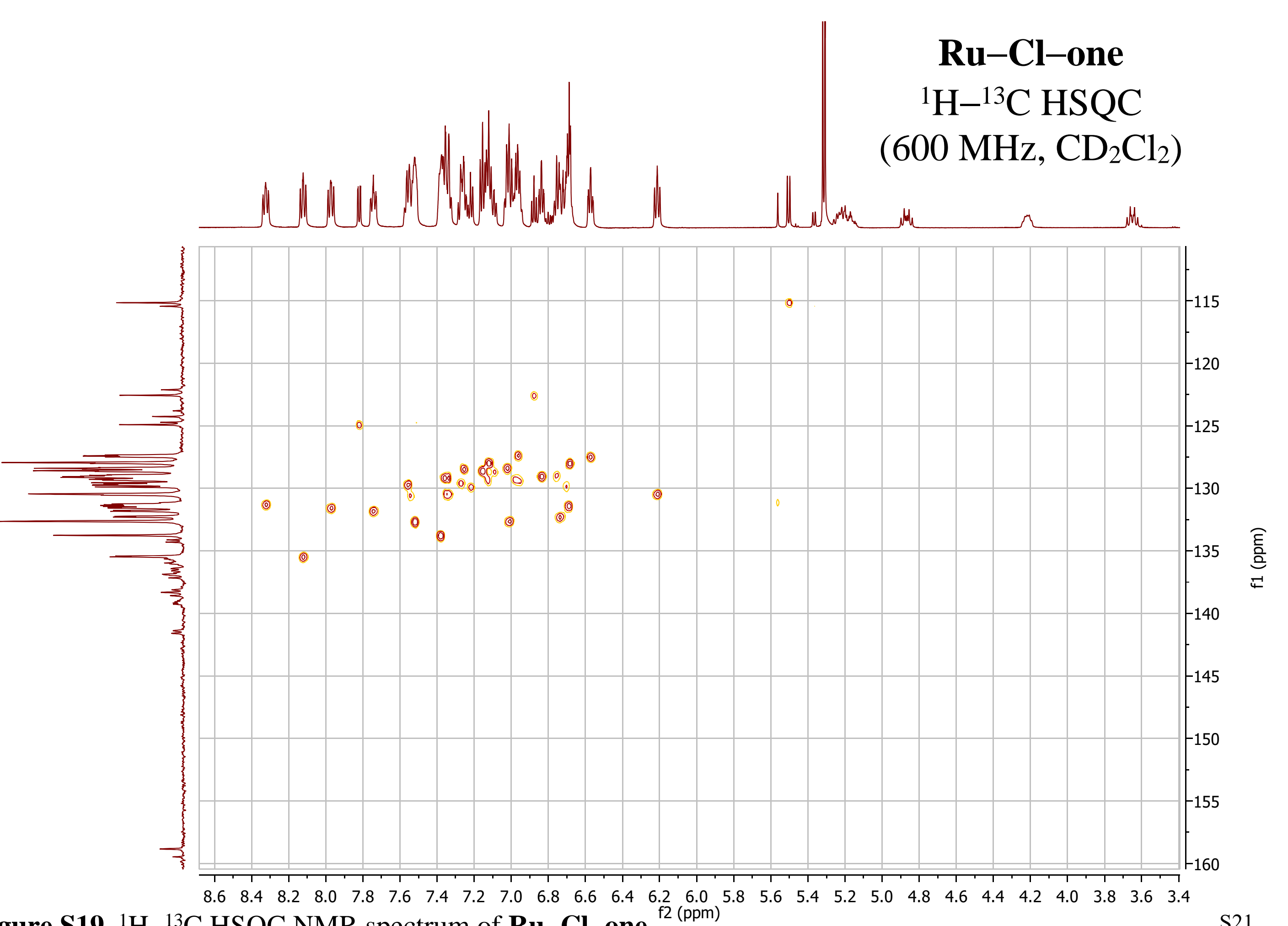

Figure S19. ${ }^{1} \mathrm{H}{ }^{13} \mathrm{C}$ HSQC NMR spectrum of Ru Cl one. 


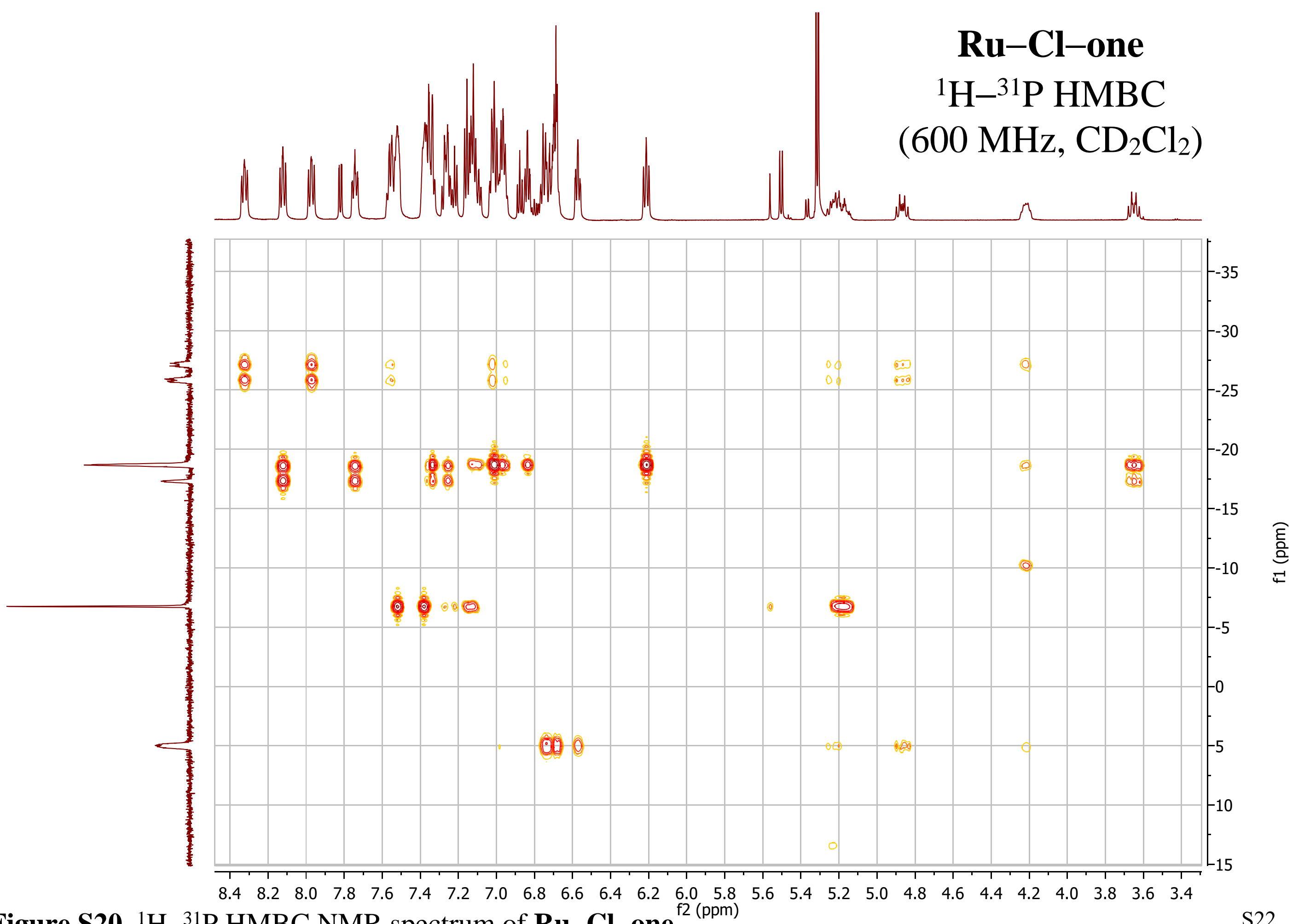

Figure S20. ${ }^{1} \mathrm{H} \quad{ }^{31} \mathrm{P}$ HMBC NMR spectrum of Ru Cl one. ${ }^{\mathrm{f} 2(\mathrm{ppm})} \quad \mathrm{S}_{22}$ 


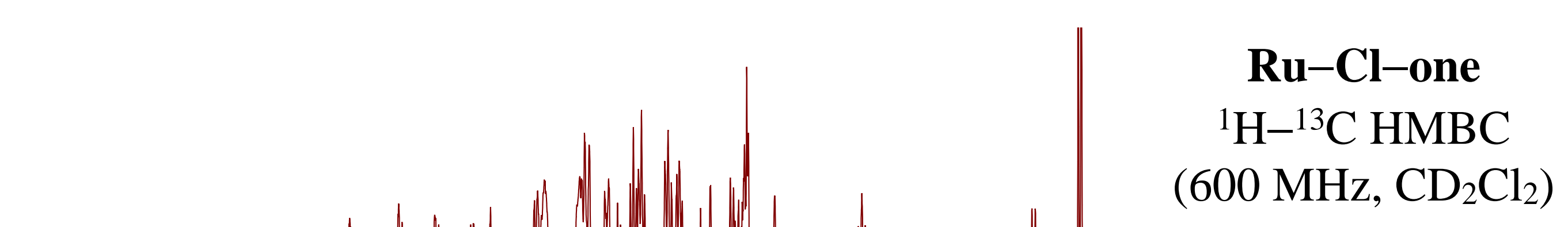




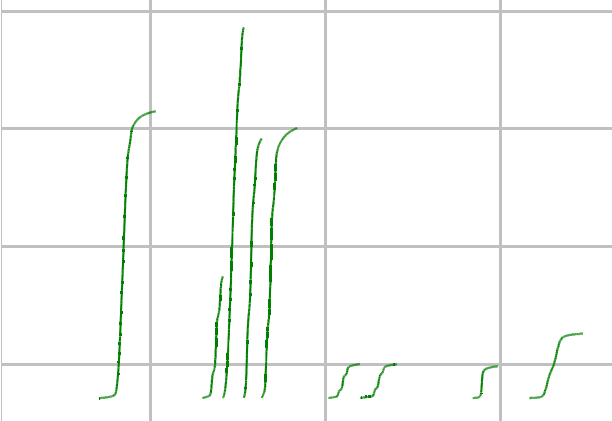

\section{Os Cl ene \\ ${ }^{1} \mathrm{H}\left(600 \mathrm{MHz}, \mathrm{CD}_{2} \mathrm{Cl}_{2}\right)$}
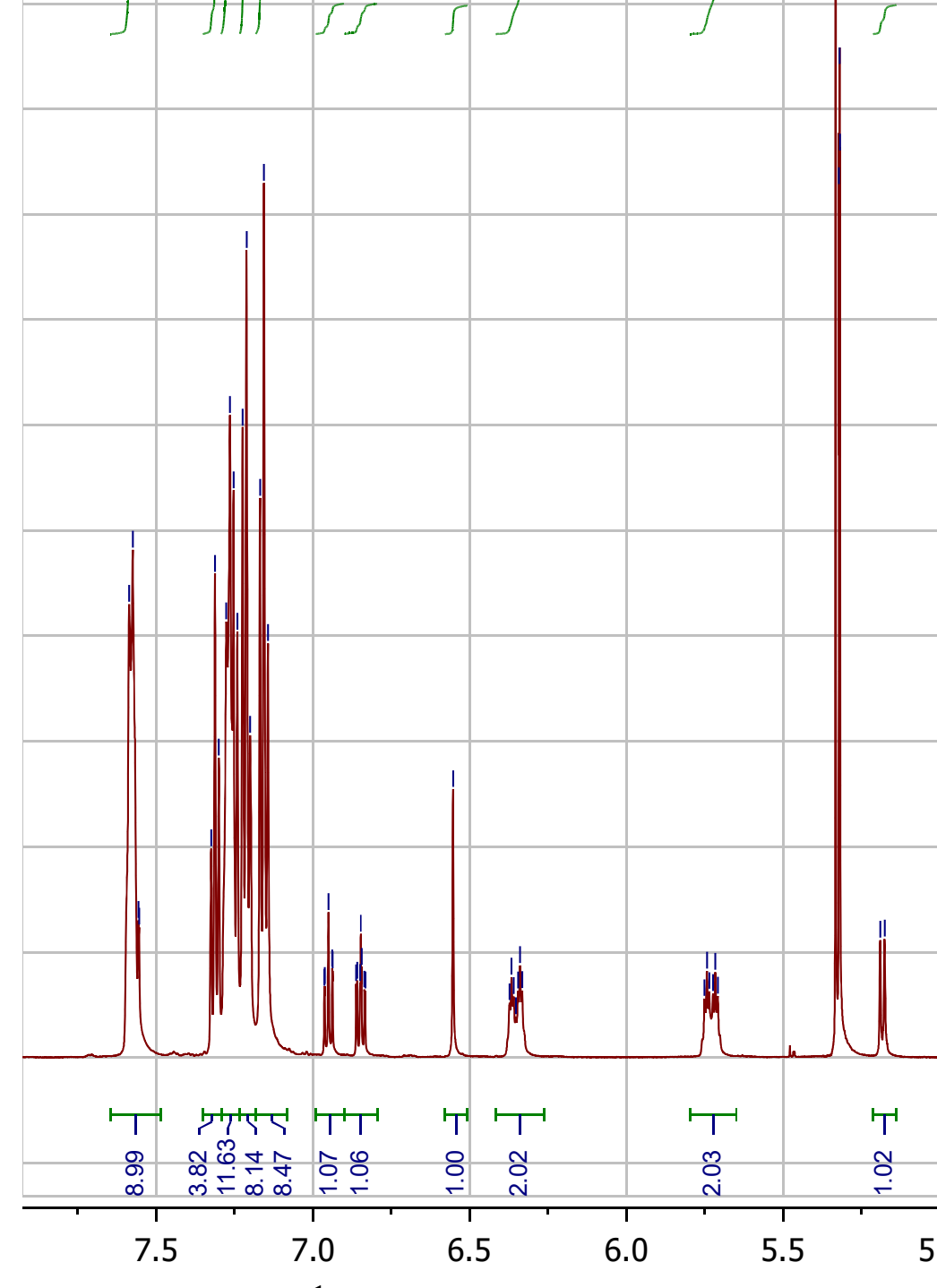

Figure S22. ${ }^{1} \mathrm{H}$ NMR spectrum of $\mathbf{O s} \mathbf{C l}$ ene. 


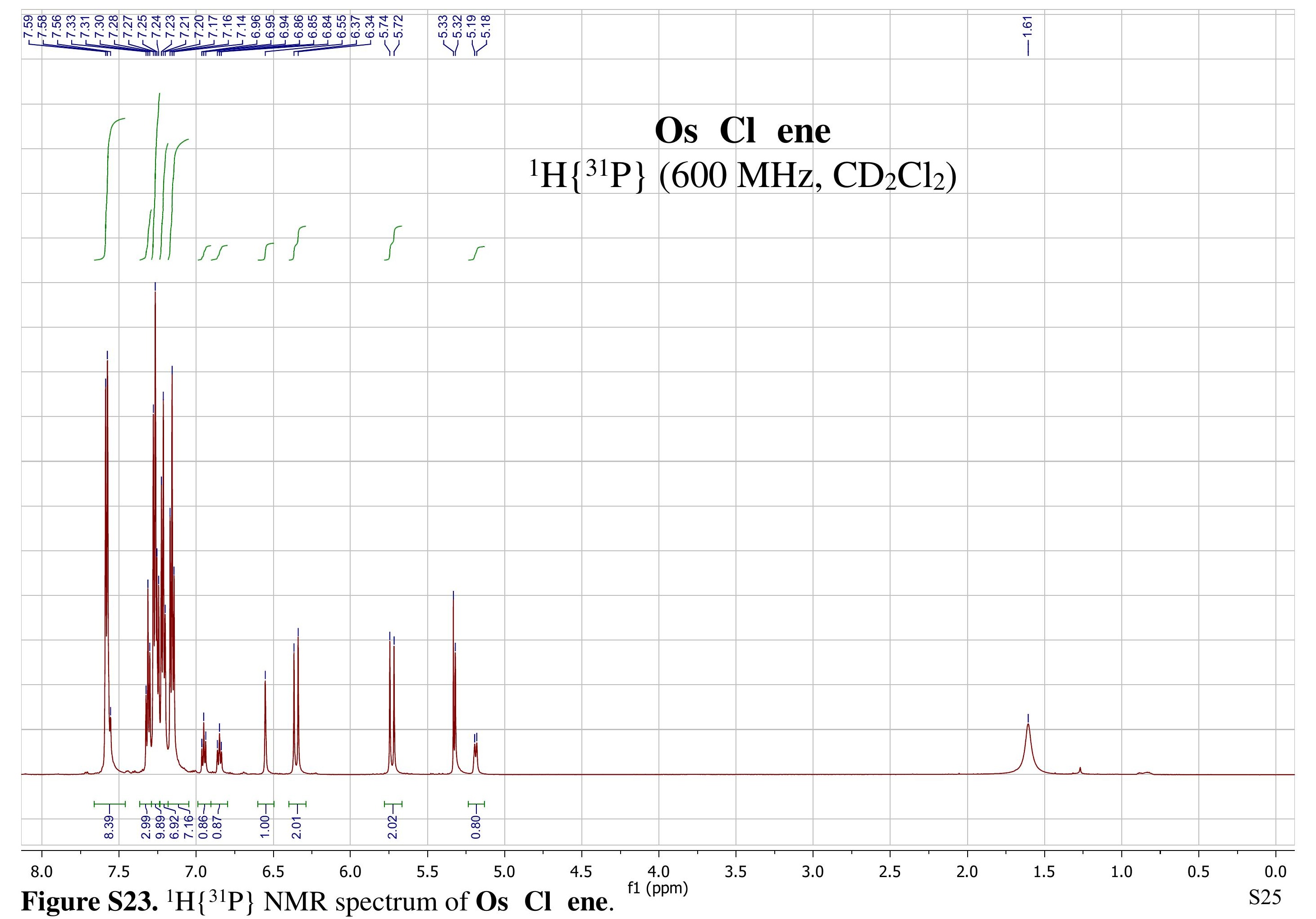




\section{Os Cl ene}

\section{${ }^{31} \mathrm{P}\left\{{ }^{1} \mathrm{H}\right\}\left(162 \mathrm{MHz}, \mathrm{CD}_{2} \mathrm{Cl}_{2}\right)$}

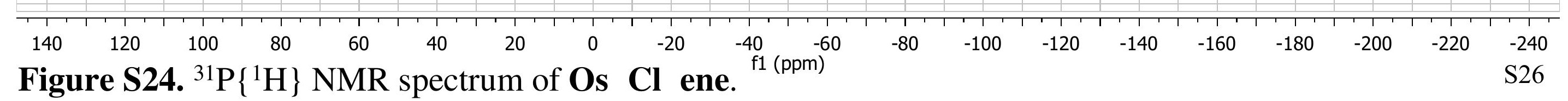




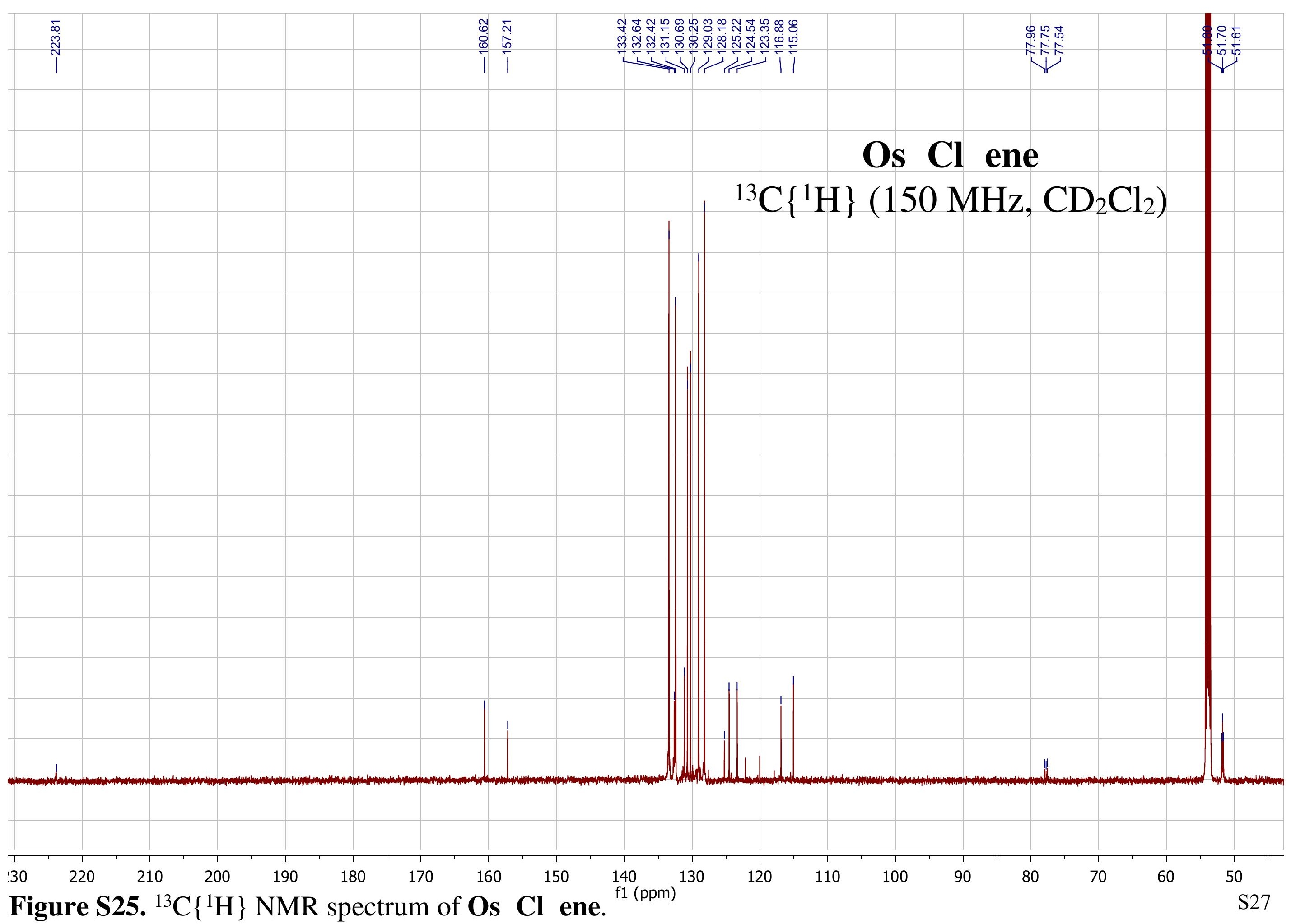




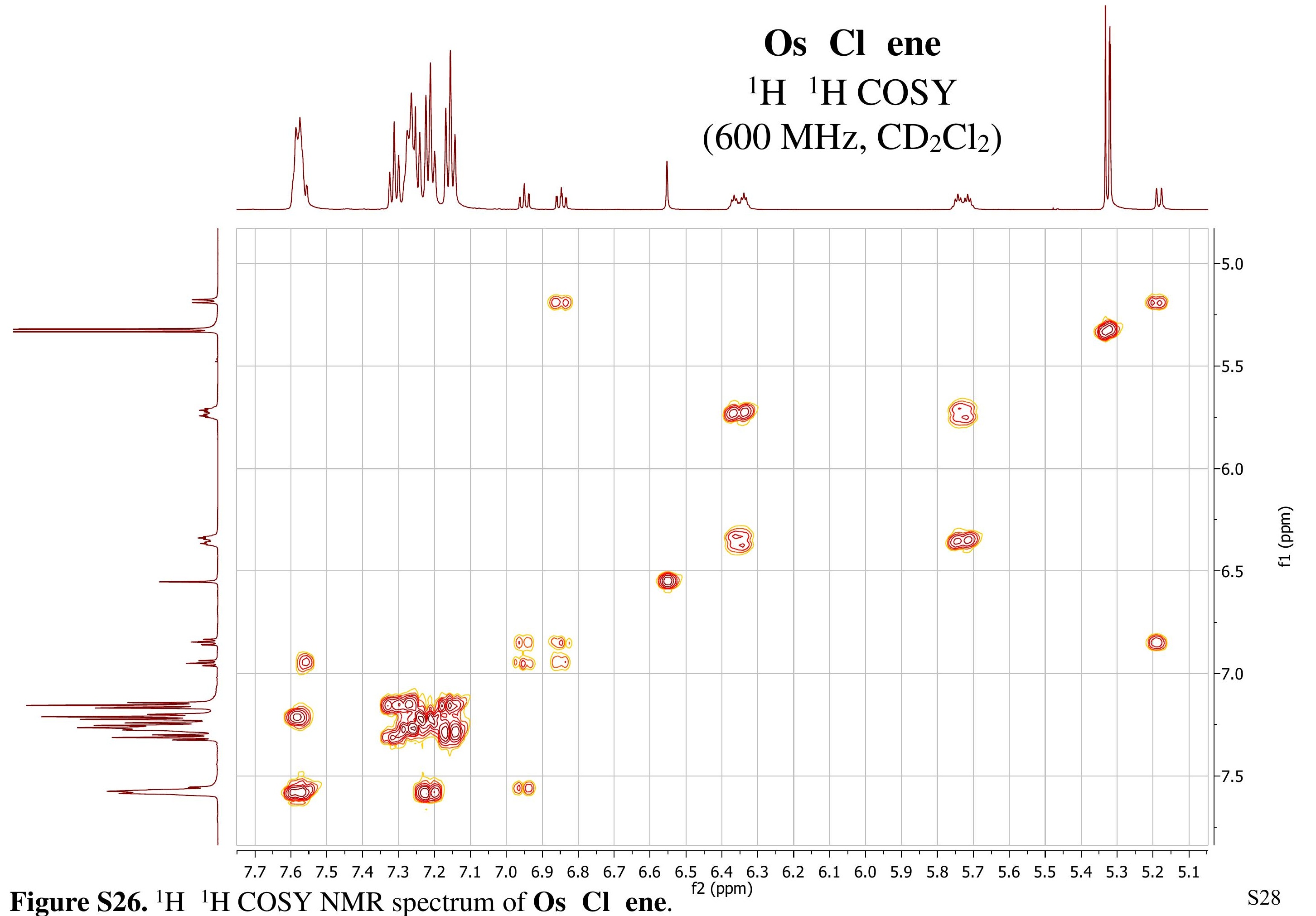




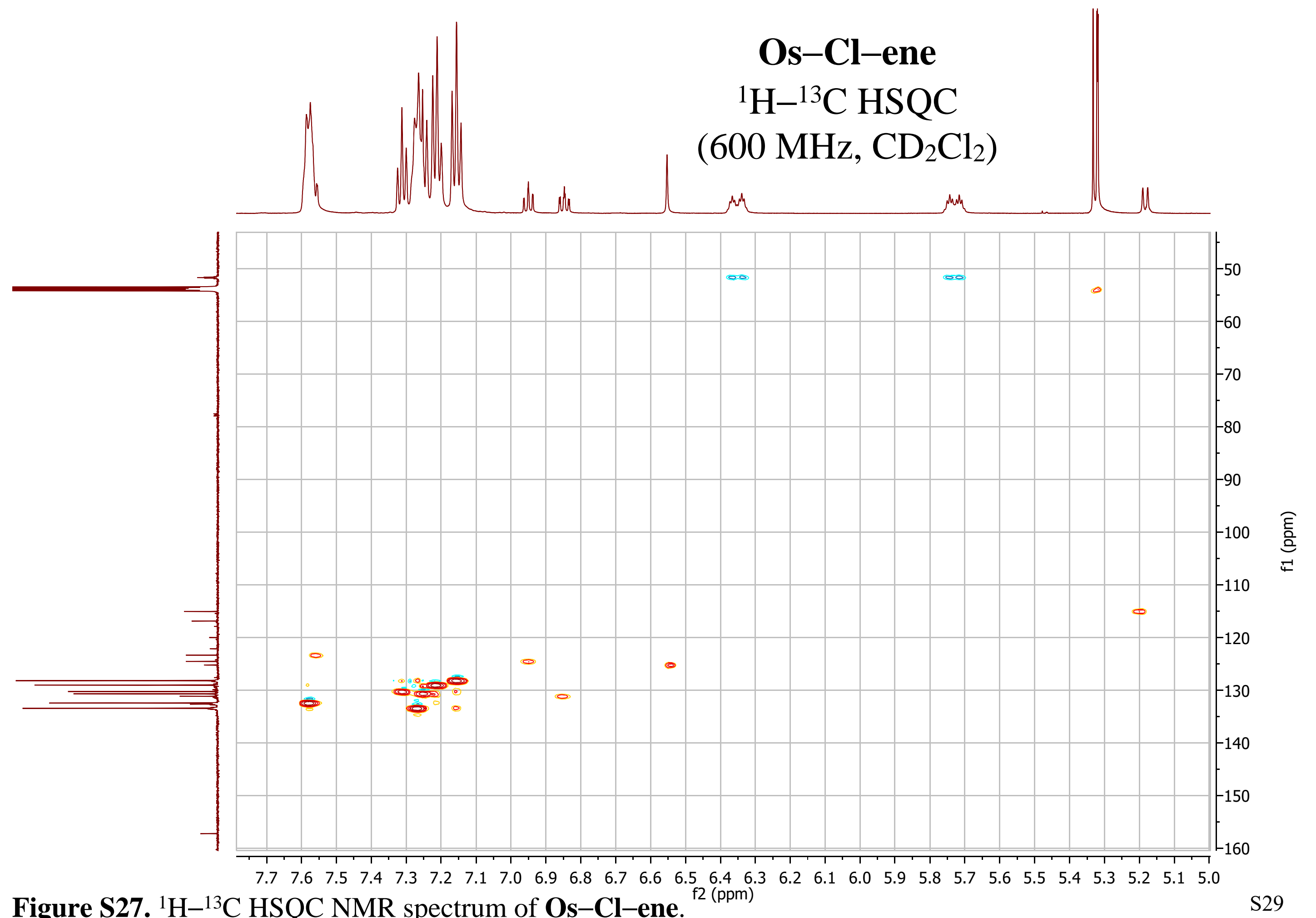




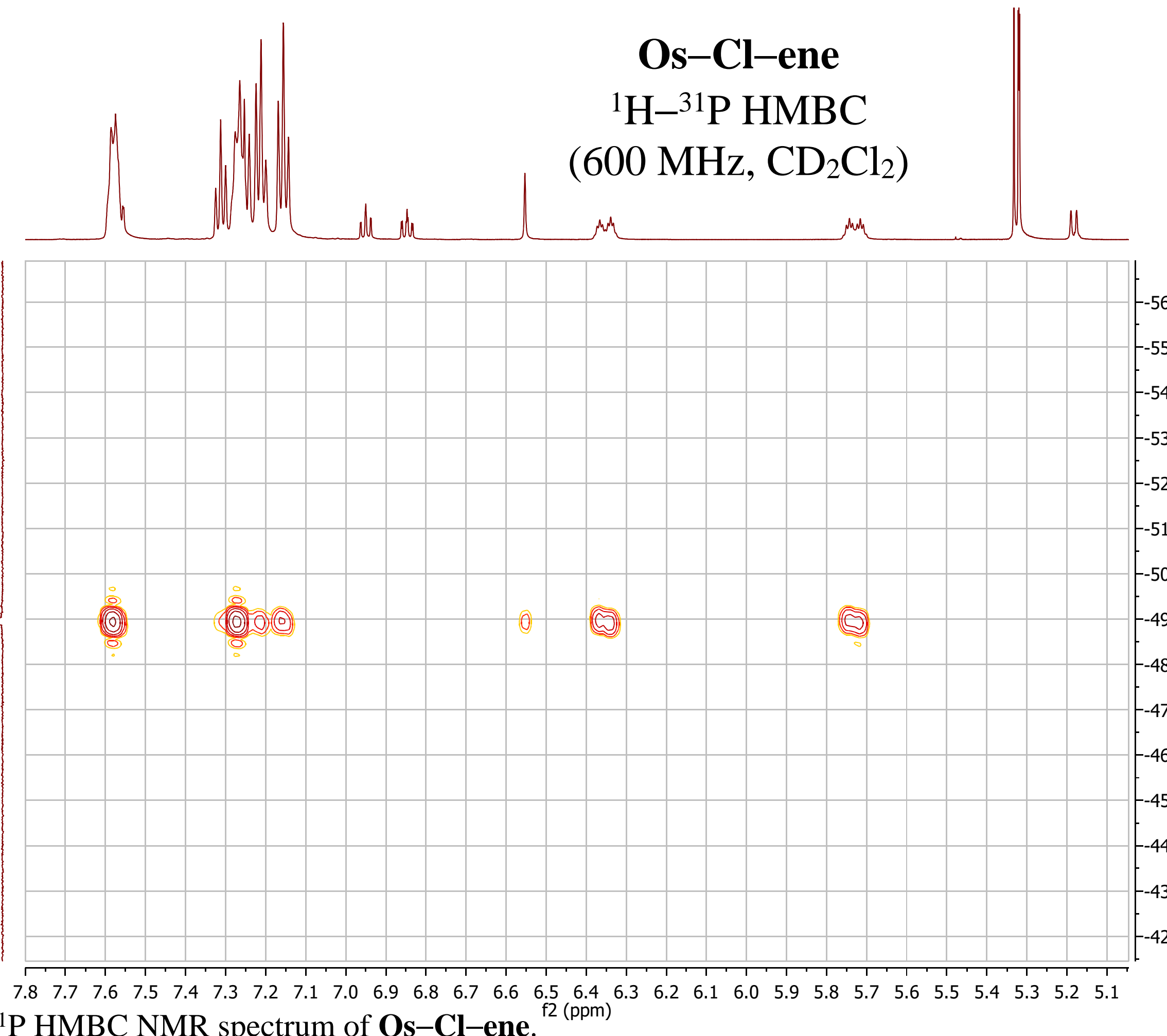




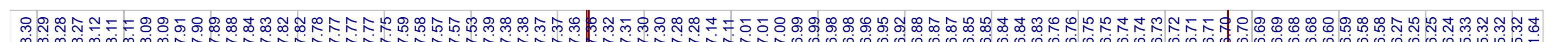
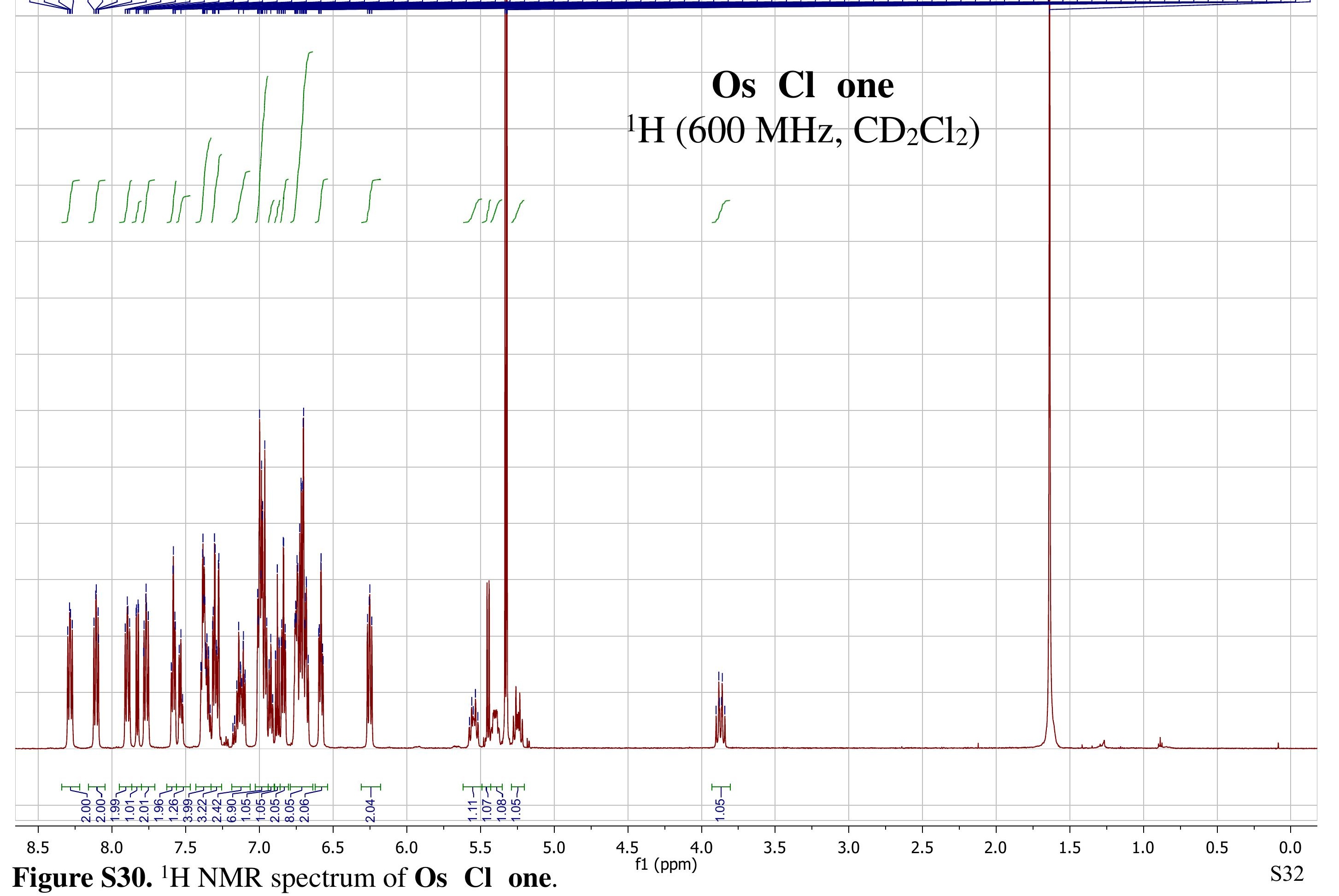

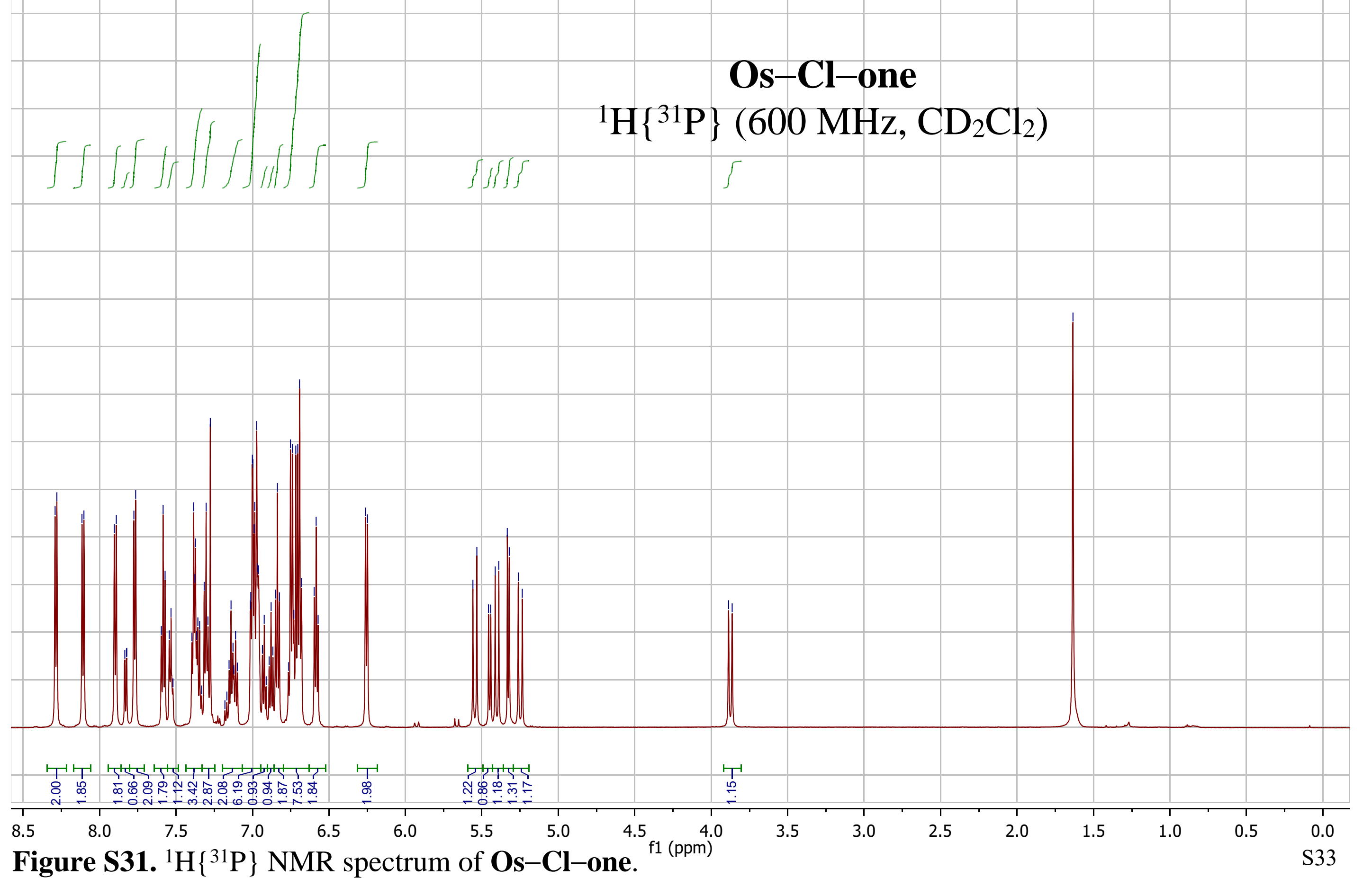


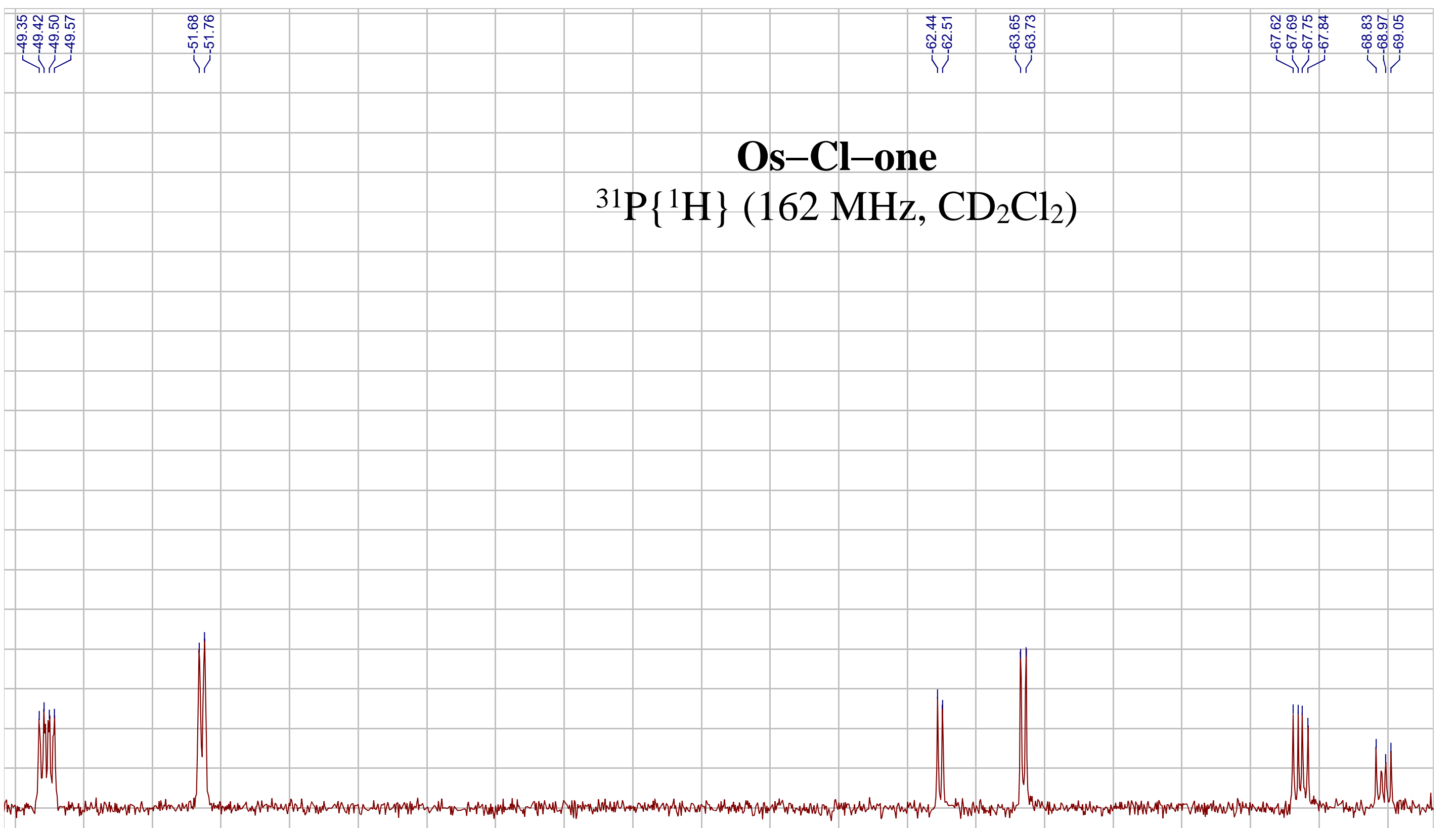




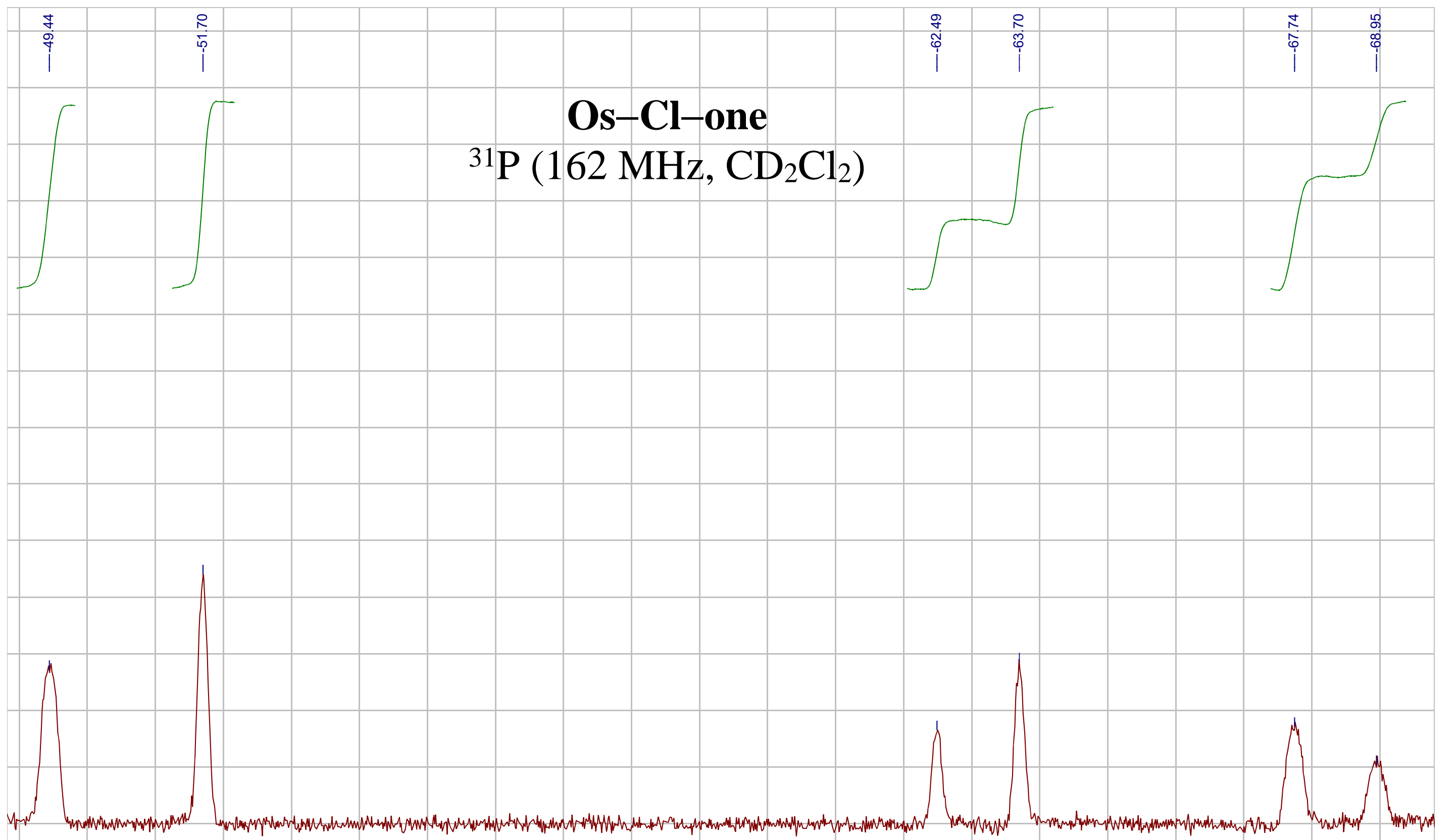

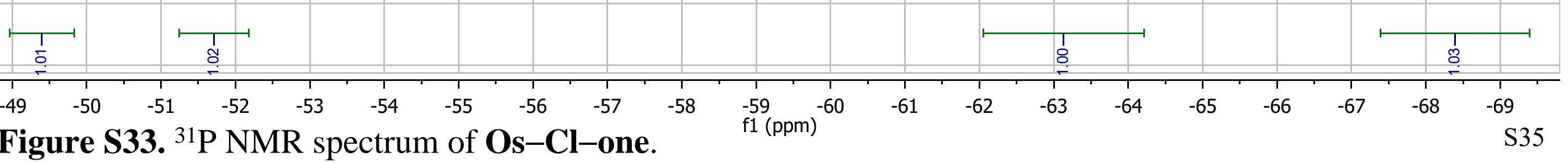




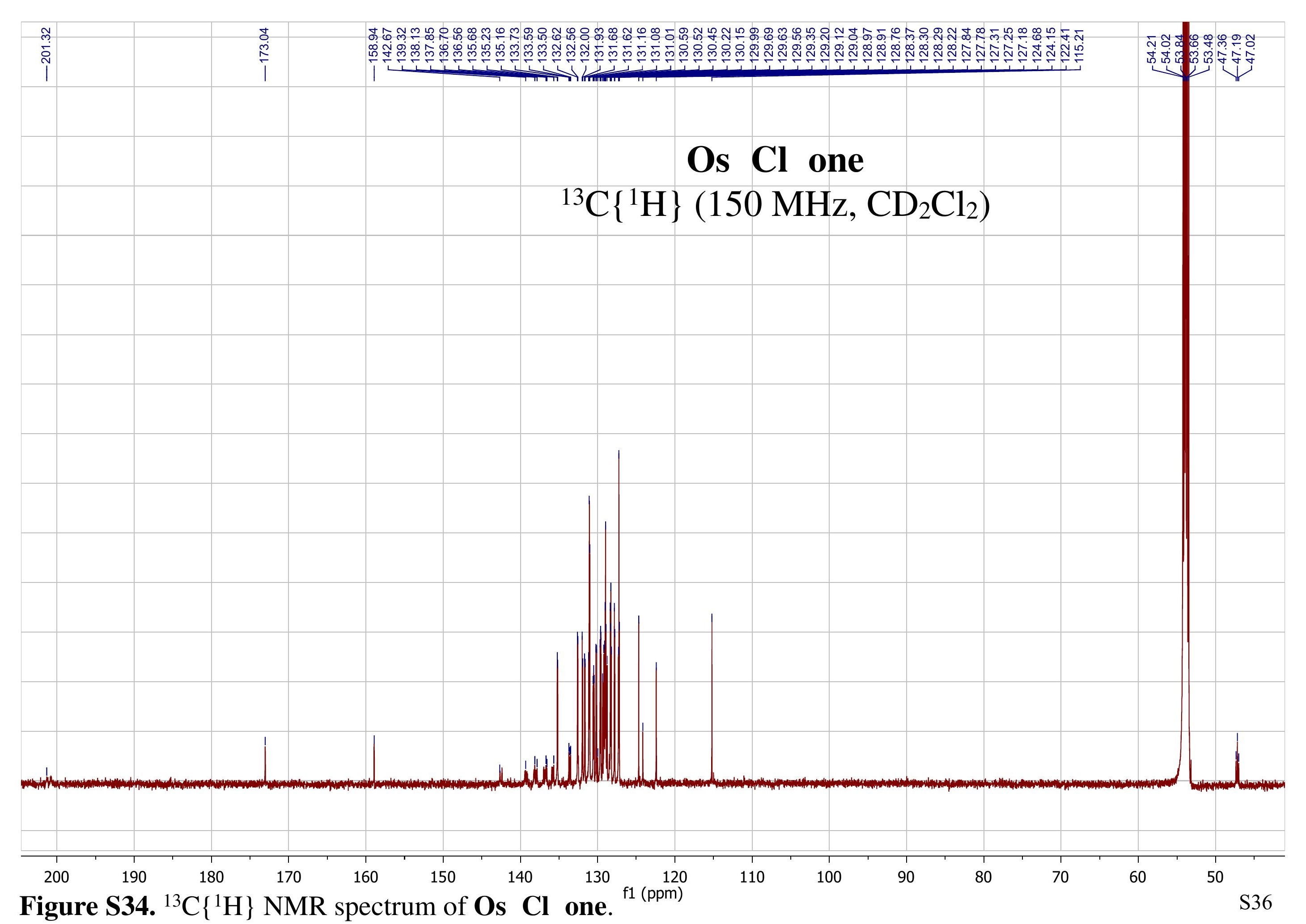




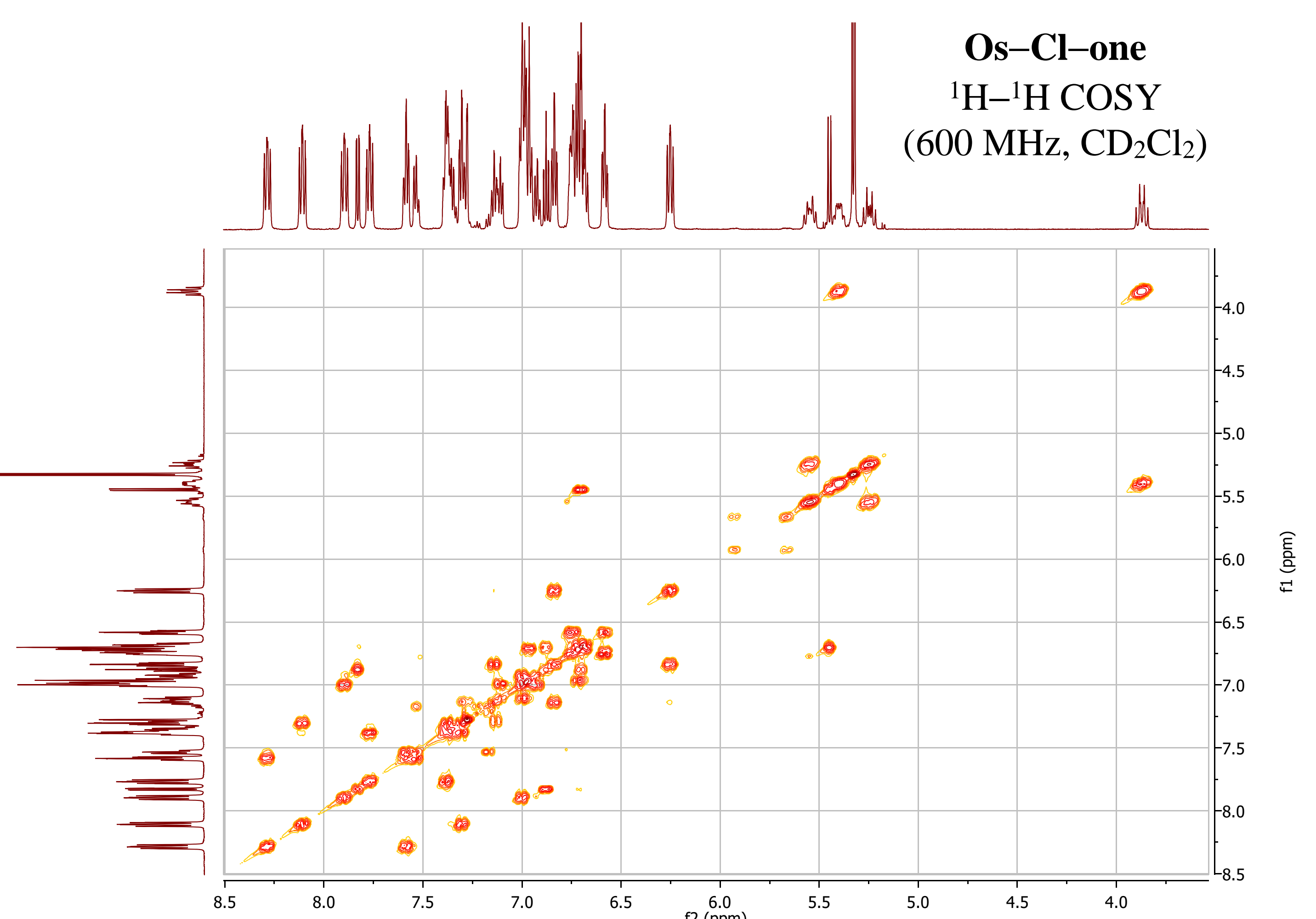

Figure $\mathbf{S 3 5 .}{ }^{1} \mathrm{H}{ }^{1} \mathrm{H}$ COSY NMR spectrum of Os Cl one. 


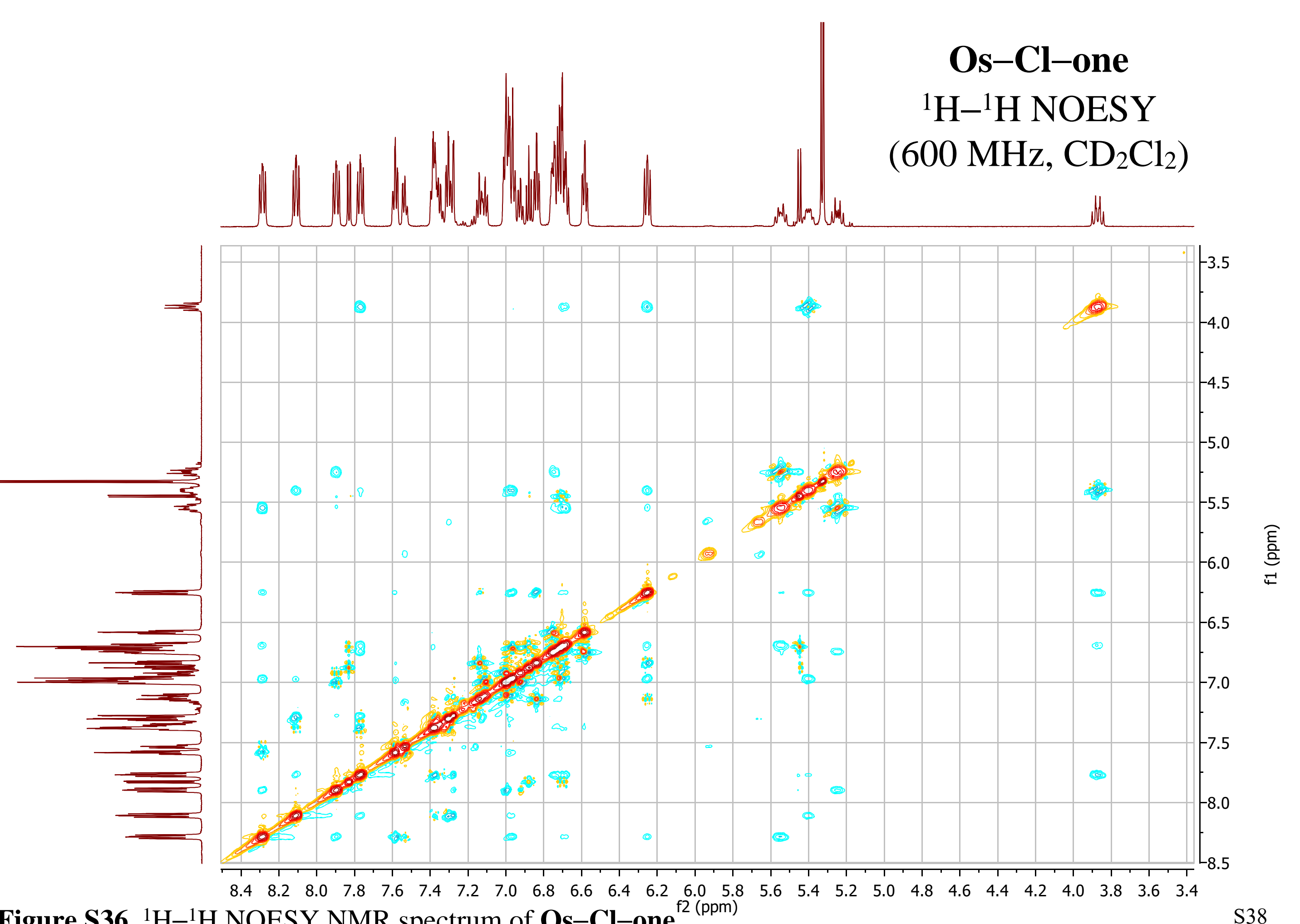

Figure S36. ${ }^{1} \mathrm{H} \quad{ }^{1} \mathrm{H}$ NOESY NMR spectrum of Os Cl one. 


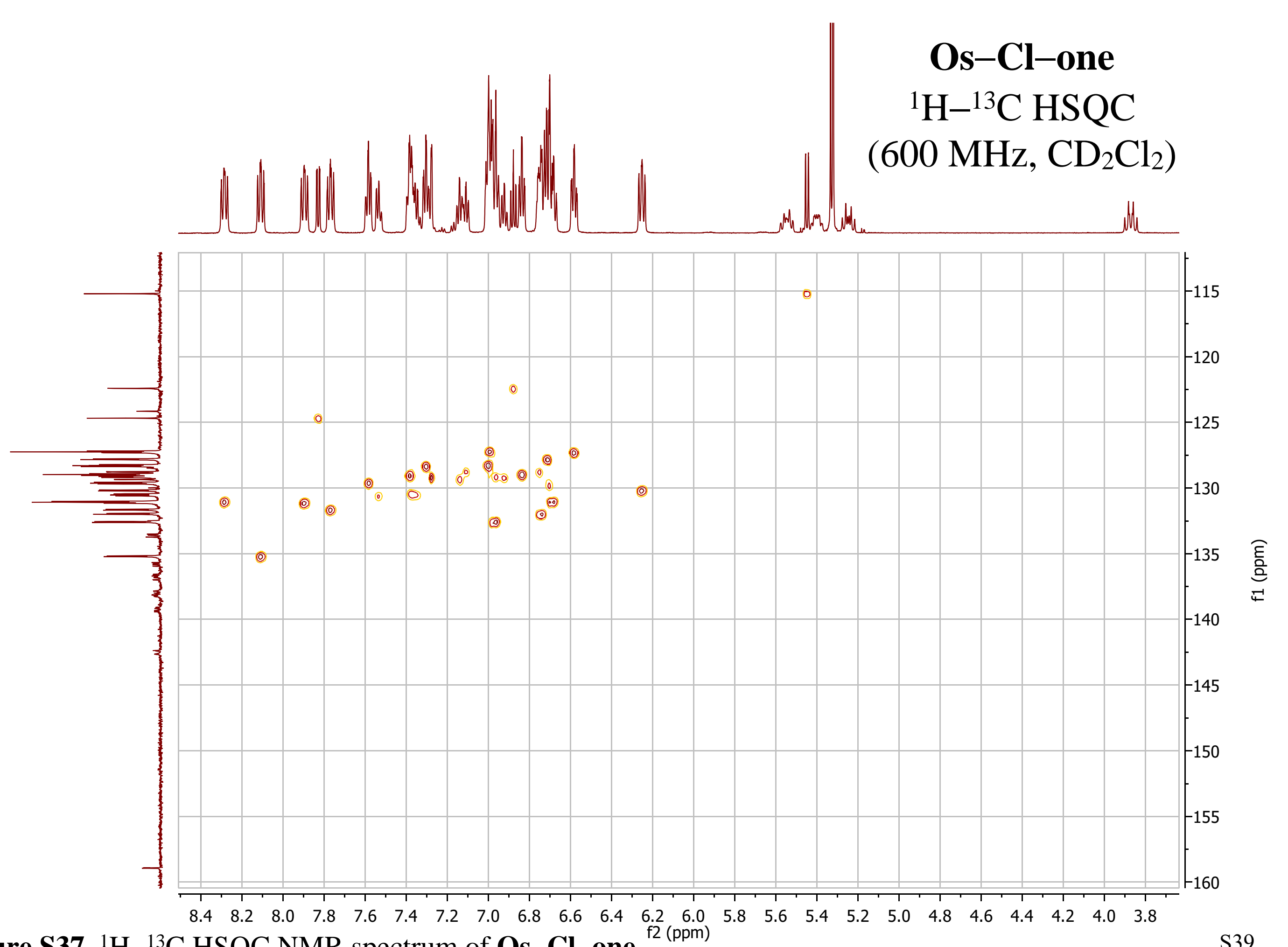

Figure S37. ${ }^{1} \mathrm{H} \quad{ }^{13} \mathrm{C}$ HSQC NMR spectrum of Os $\mathbf{C l}$ one. ${ }^{\mathrm{f} 2(\mathrm{ppm})}$ 


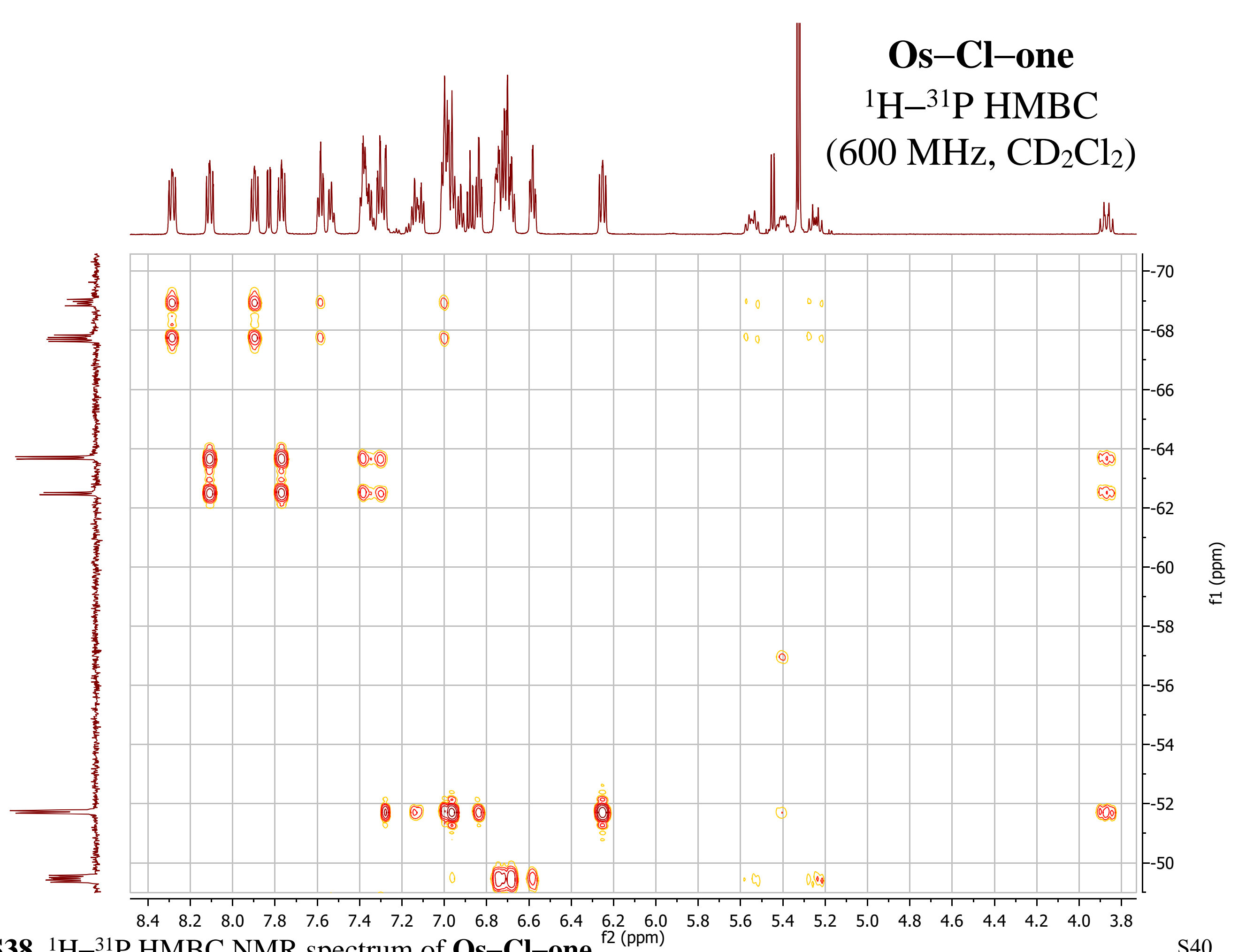

Figure S38. ${ }^{1} \mathrm{H}{ }^{31} \mathrm{P}$ HMBC NMR spectrum of $\mathrm{Os} \mathbf{C l}$ one. 


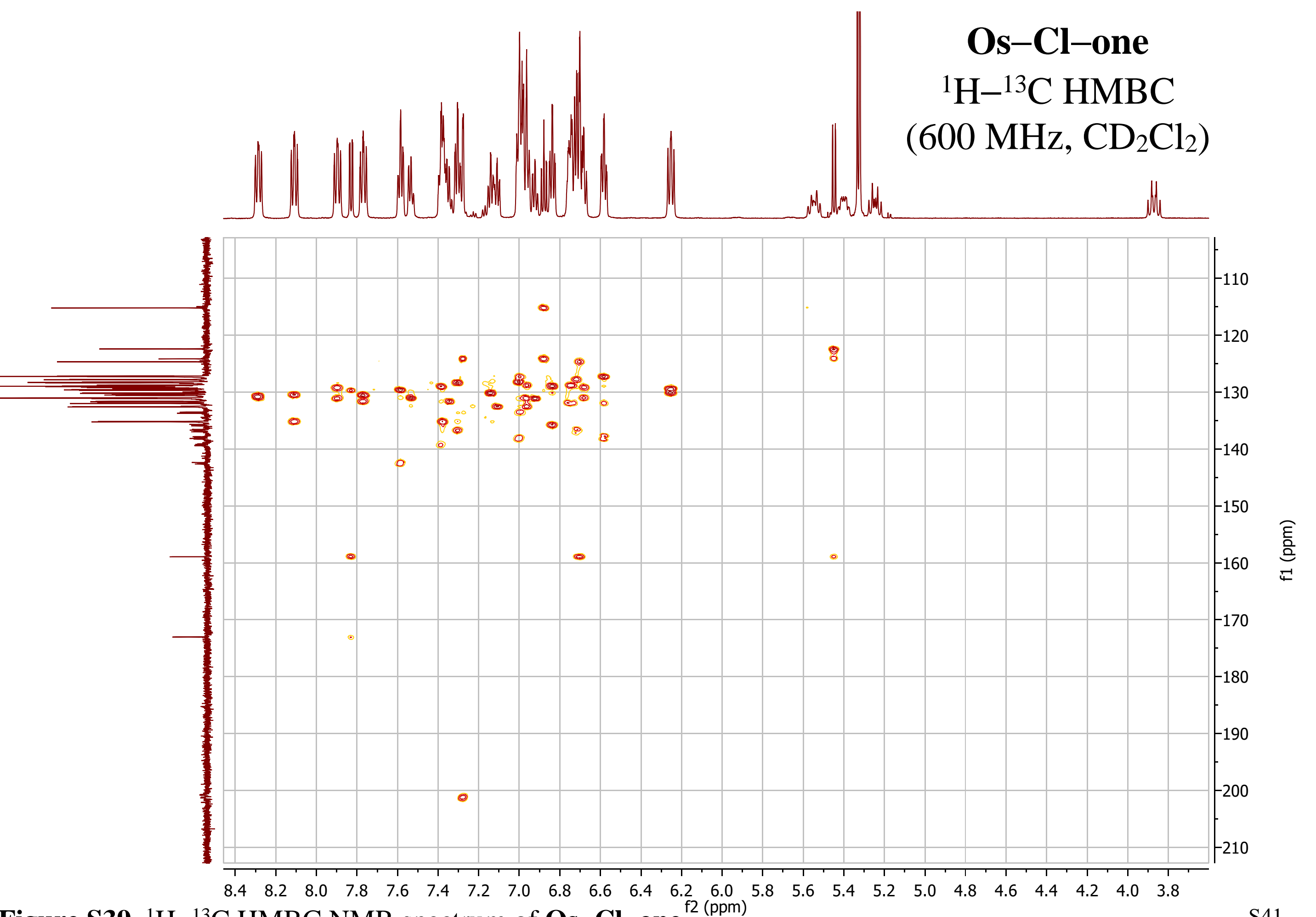

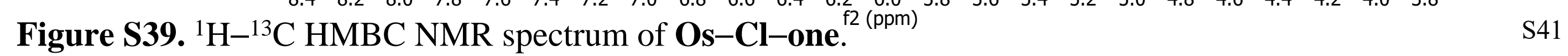



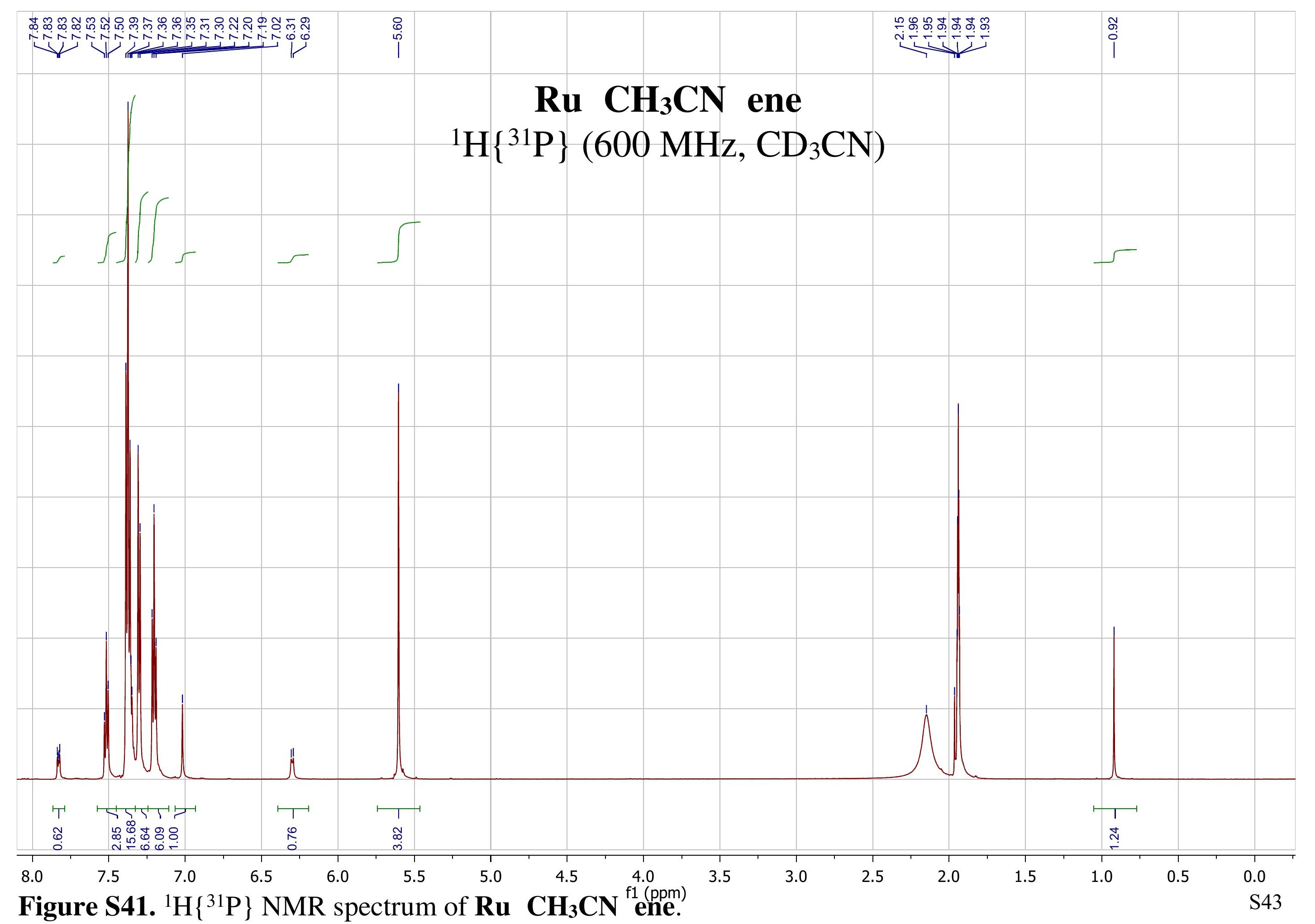


\section{$\mathrm{Ru} \mathrm{CH}_{3} \mathrm{CN}$ ene ${ }^{31} \mathrm{P}\left\{{ }^{1} \mathrm{H}\right\}\left(162 \mathrm{MHz}, \mathrm{CD}_{3} \mathrm{CN}\right)$}

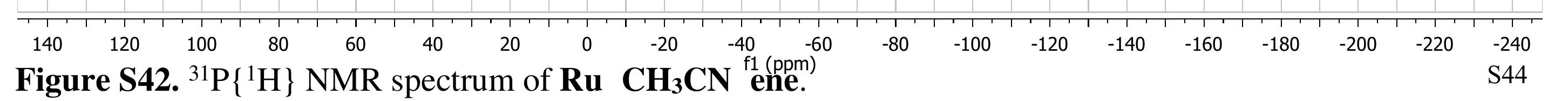




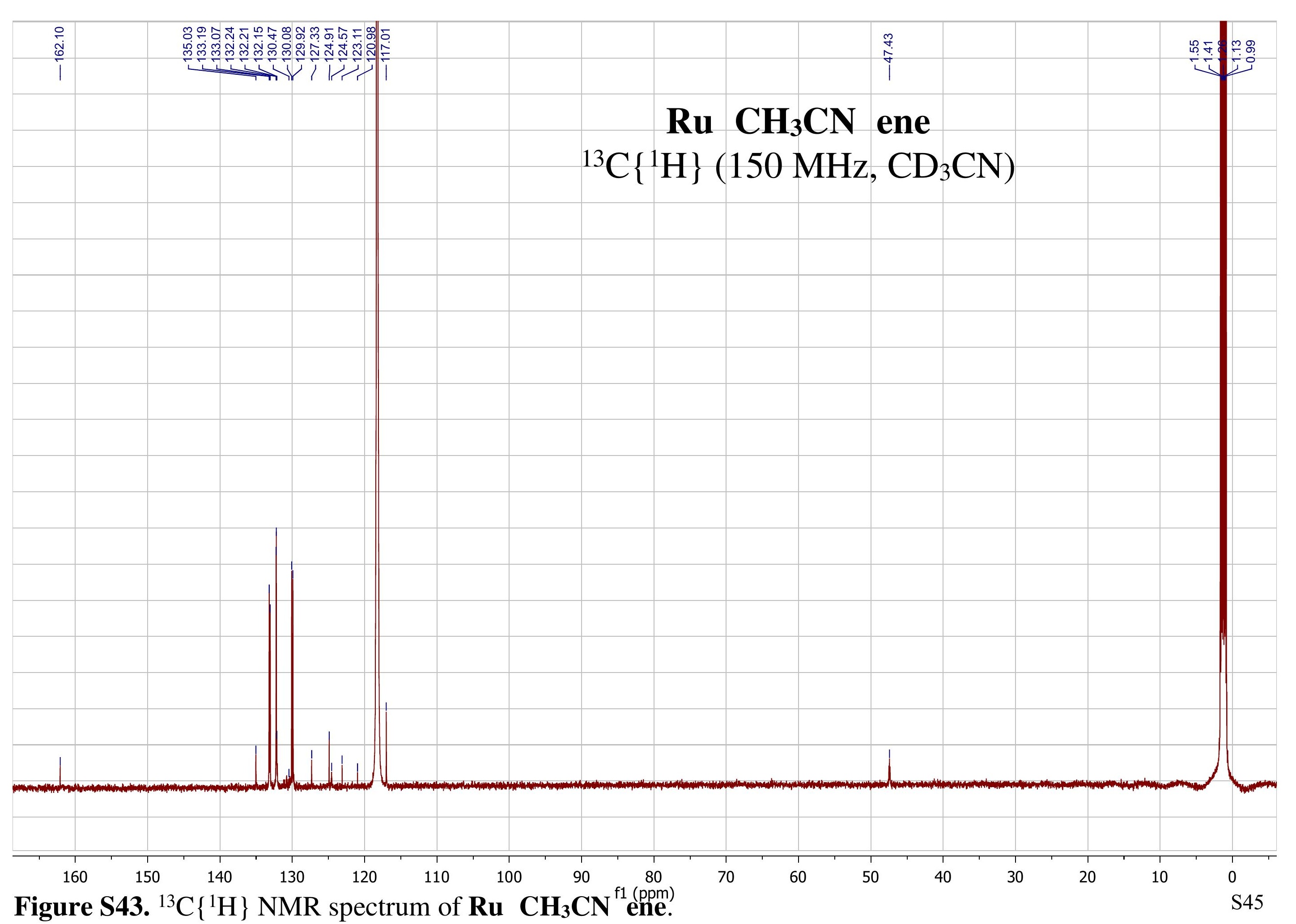




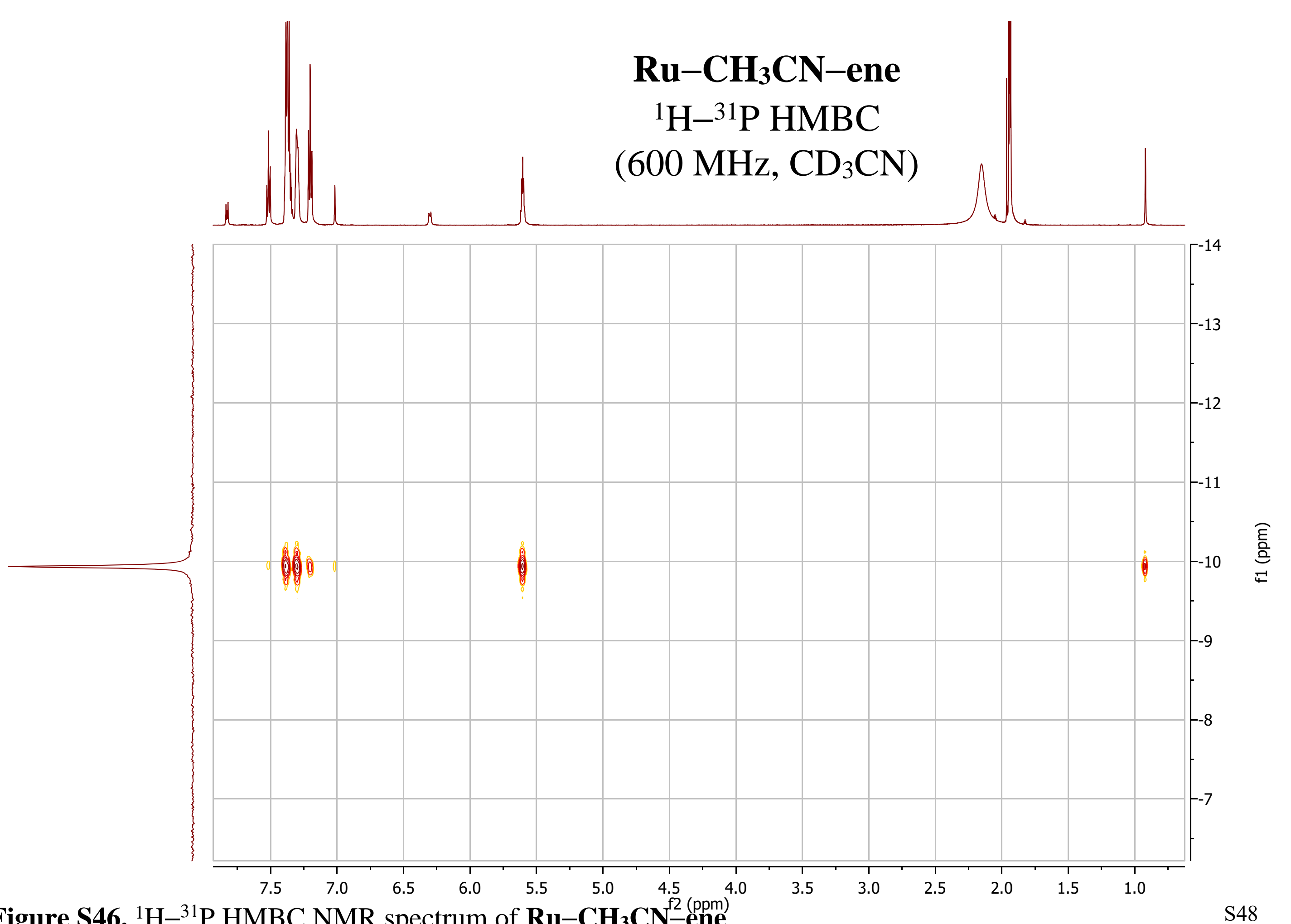

Figure S46. ${ }^{1} \mathrm{H}^{31} \mathrm{P}$ HMBC NMR spectrum of $\mathbf{R u} \mathbf{C H}_{3} \mathbf{C N}^{\mathrm{f} 2}$ (ppme. 


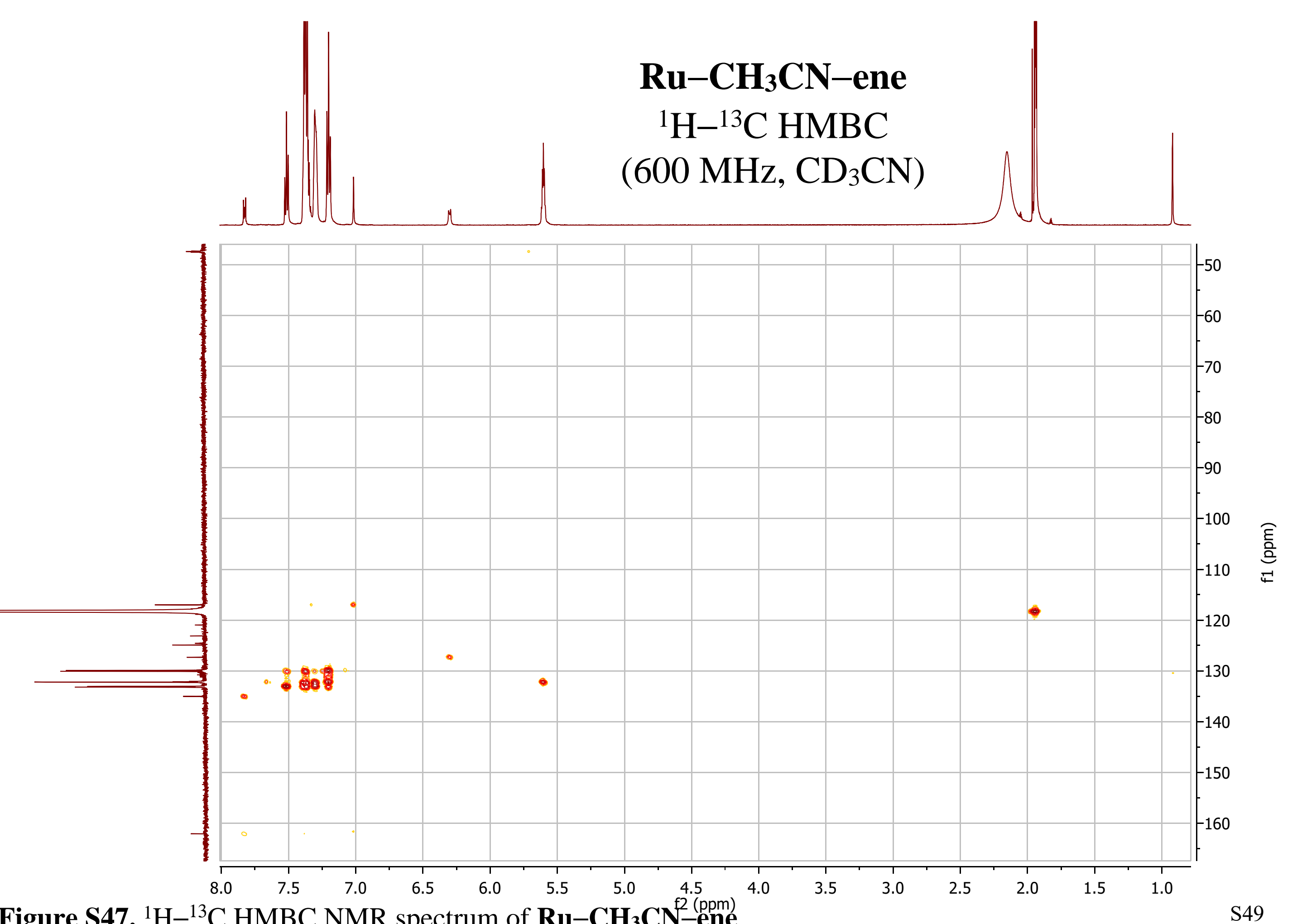

Figure S47. ${ }^{1} \mathrm{H}{ }^{13} \mathrm{C}$ HMBC NMR spectrum of $\mathbf{R u} \mathbf{C H}_{3} \mathbf{C N}^{\mathrm{f}^{2} \text { (ppme. }}$ 


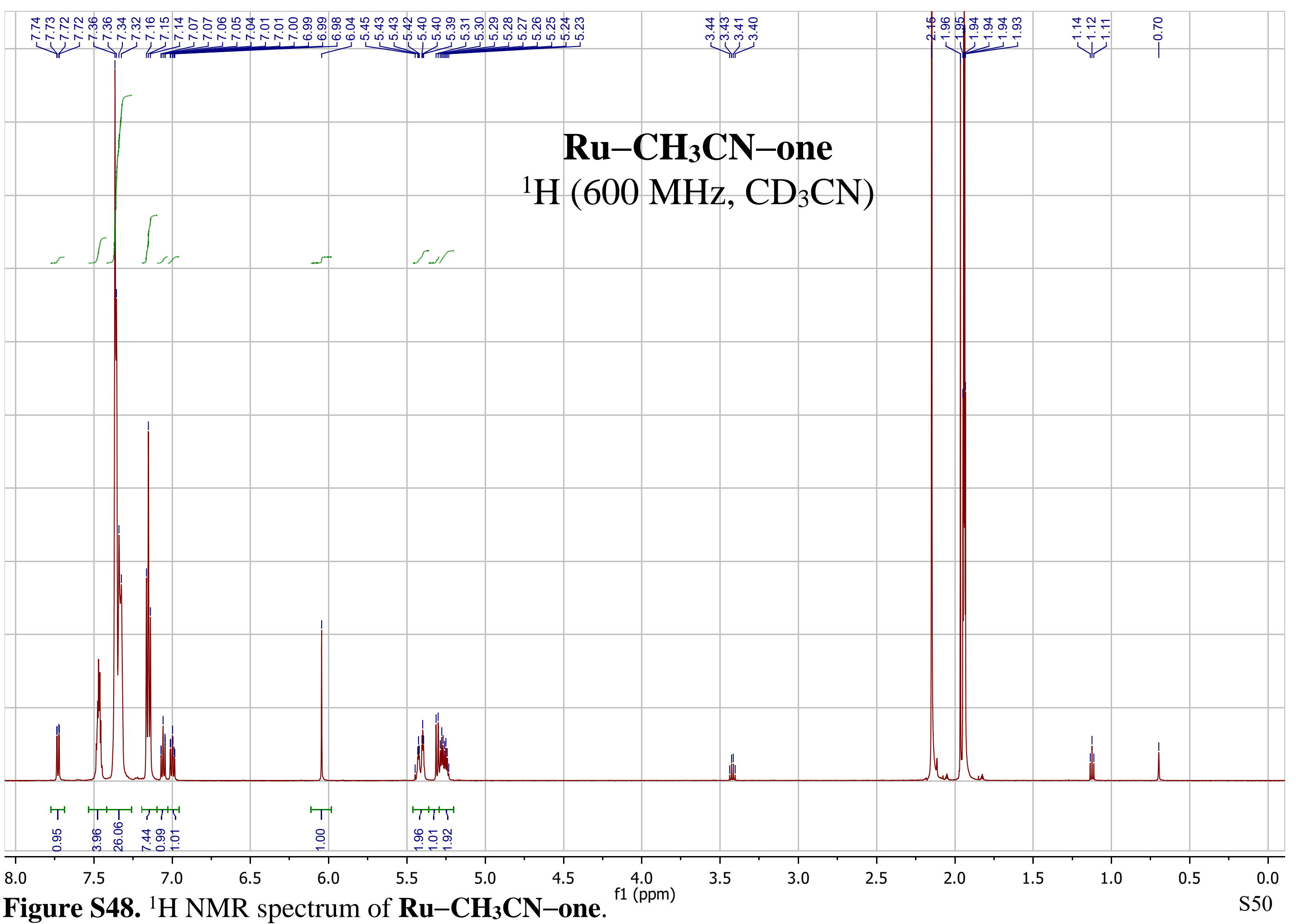




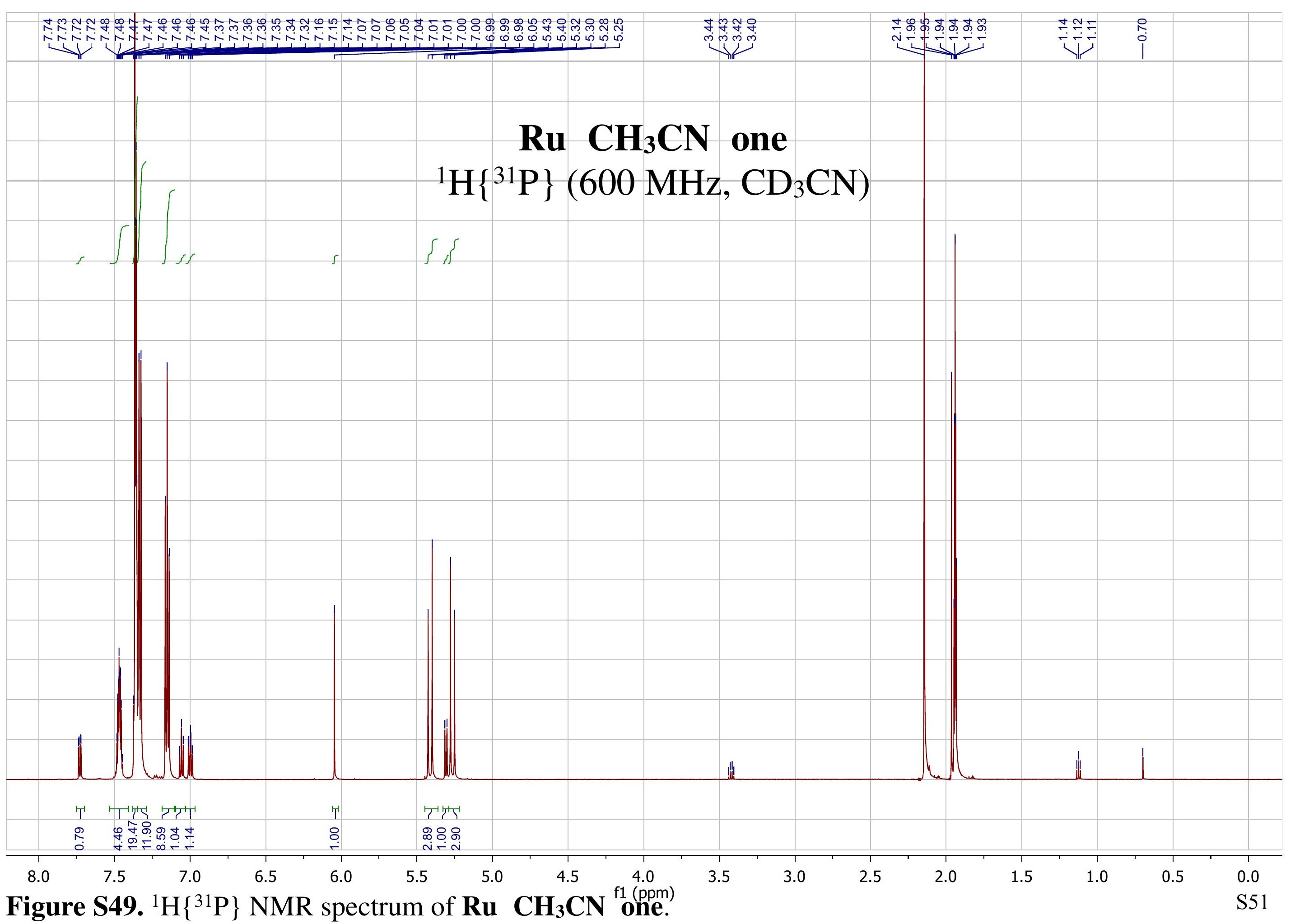




\section{$\mathrm{Ru} \mathrm{CH}_{3} \mathrm{CN}$ one ${ }^{31} \mathrm{P}\left\{{ }^{1} \mathrm{H}\right\}\left(162 \mathrm{MHz}, \mathrm{CD}_{3} \mathrm{CN}\right)$}

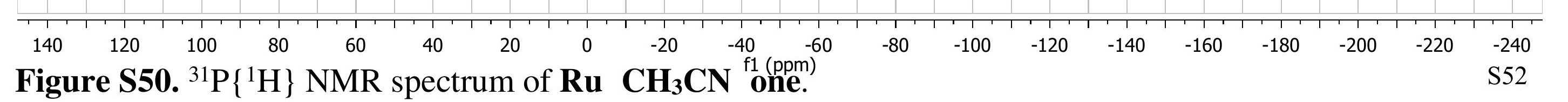




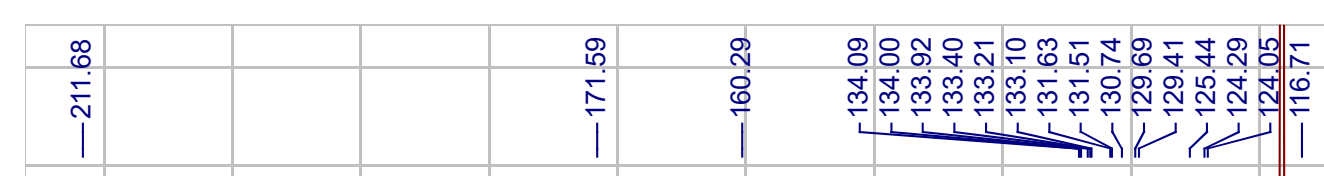

\section{$\mathrm{Ru} \mathrm{CH}_{3} \mathrm{CN}$ one}

\section{${ }^{13} \mathrm{C}\left\{{ }^{1} \mathrm{H}\right\}\left(150 \mathrm{MHz}, \mathrm{CD}_{3} \mathrm{CN}\right)$}
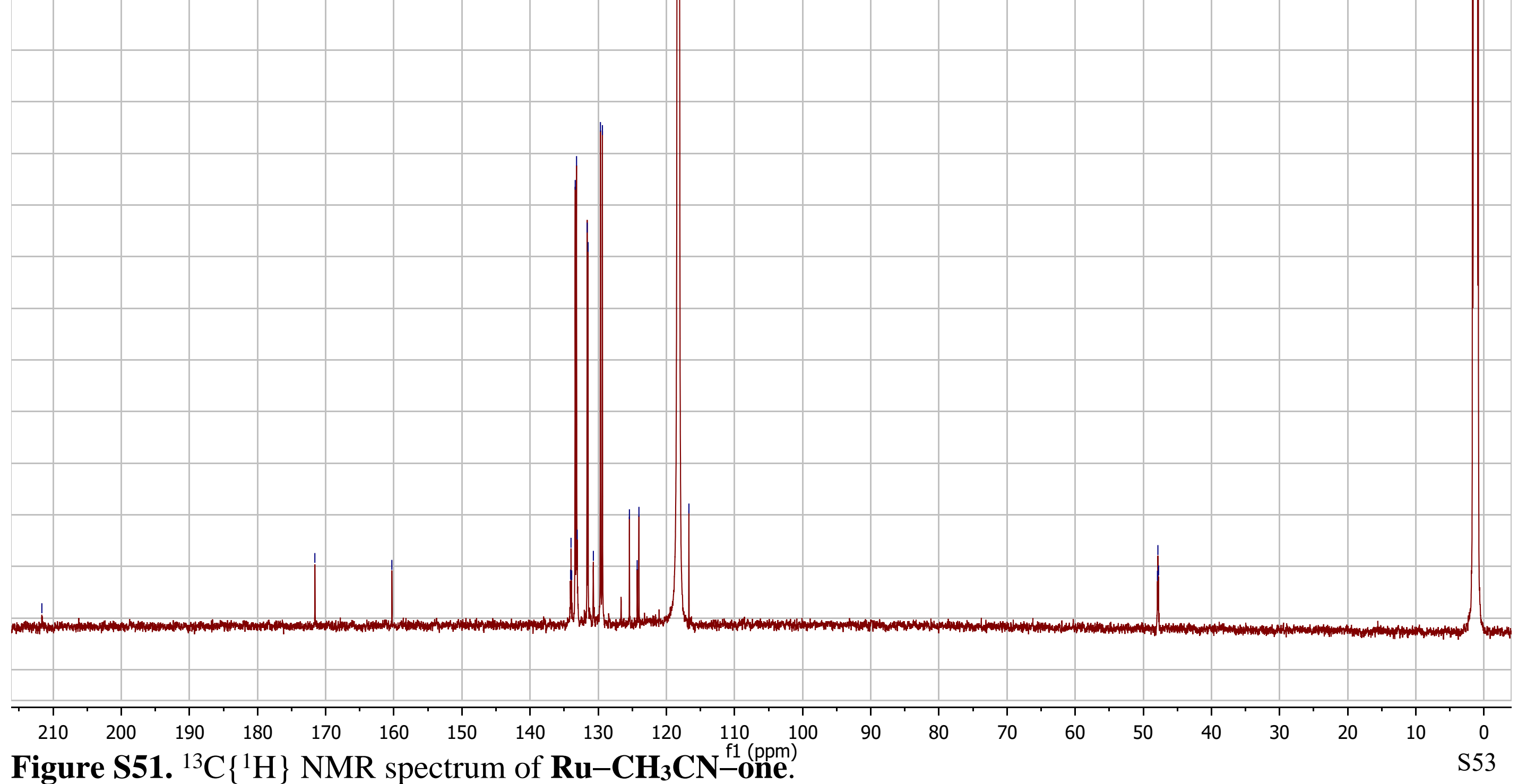


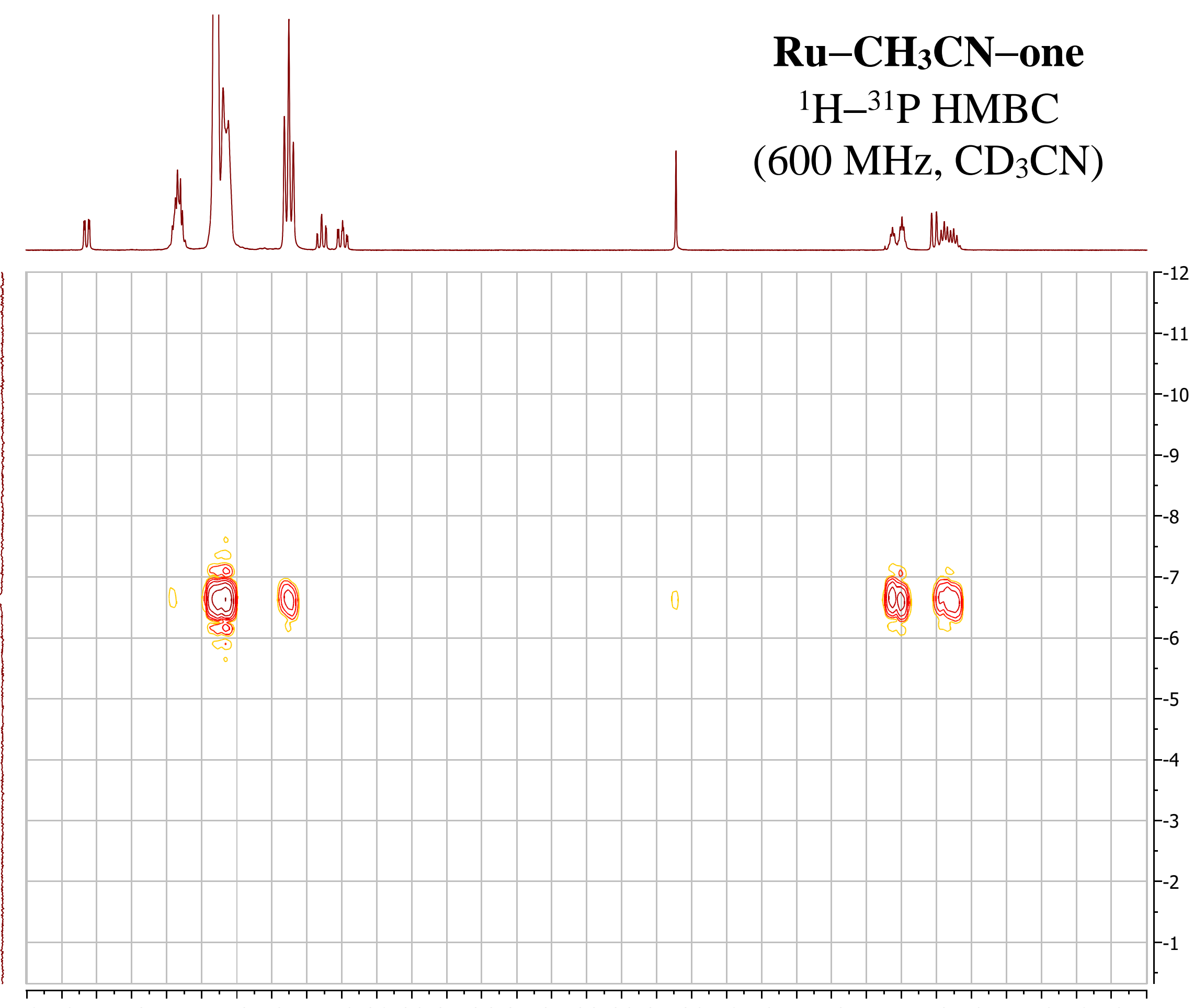

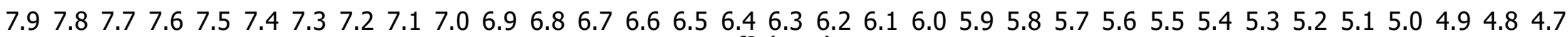
Figure S54. ${ }^{1} \mathrm{H}{ }^{31} \mathrm{P}$ HMBC NMR spectrum of $\mathbf{R u} \mathbf{C H}_{3} \mathbf{C N}^{2}$ (pone. 


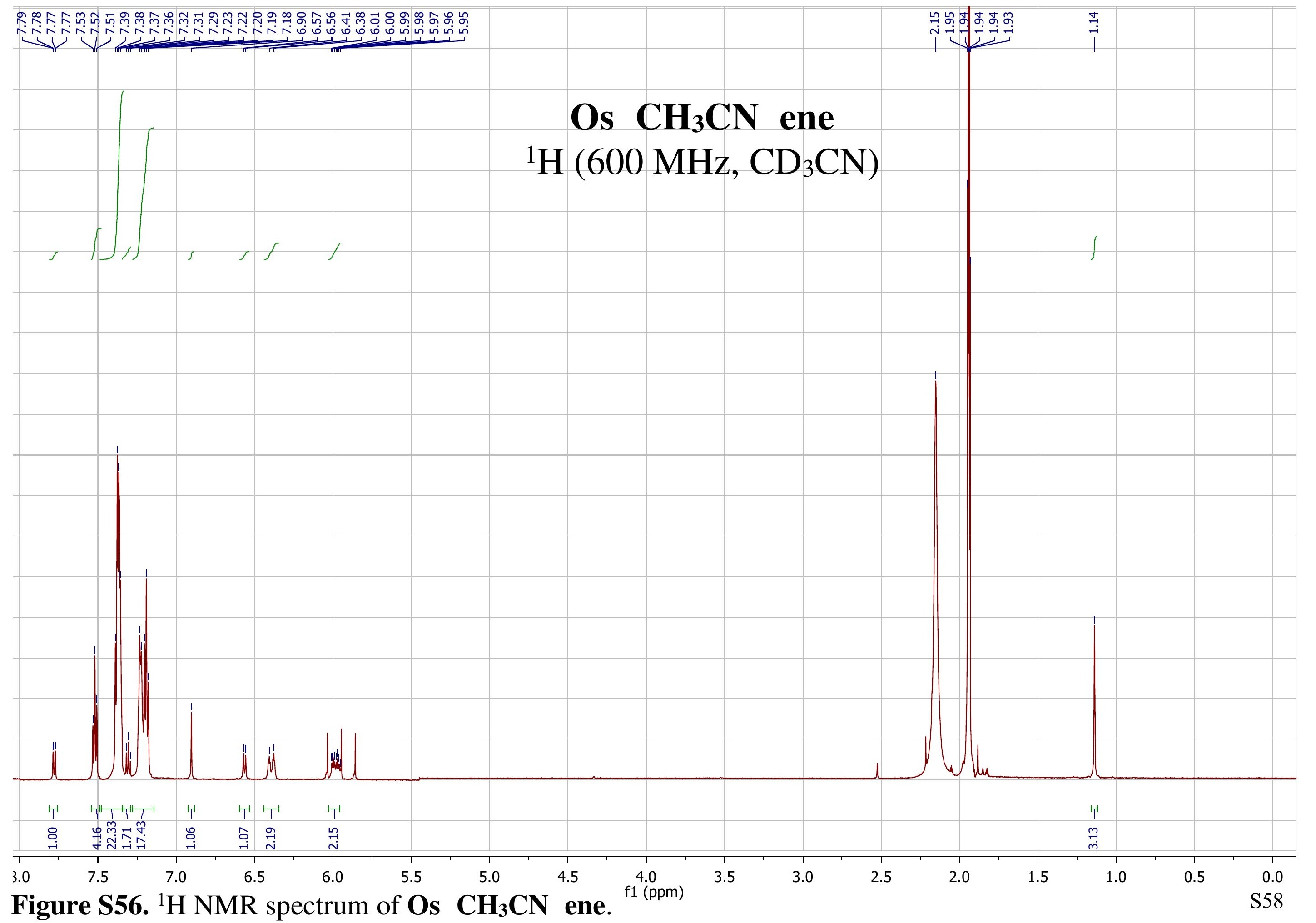




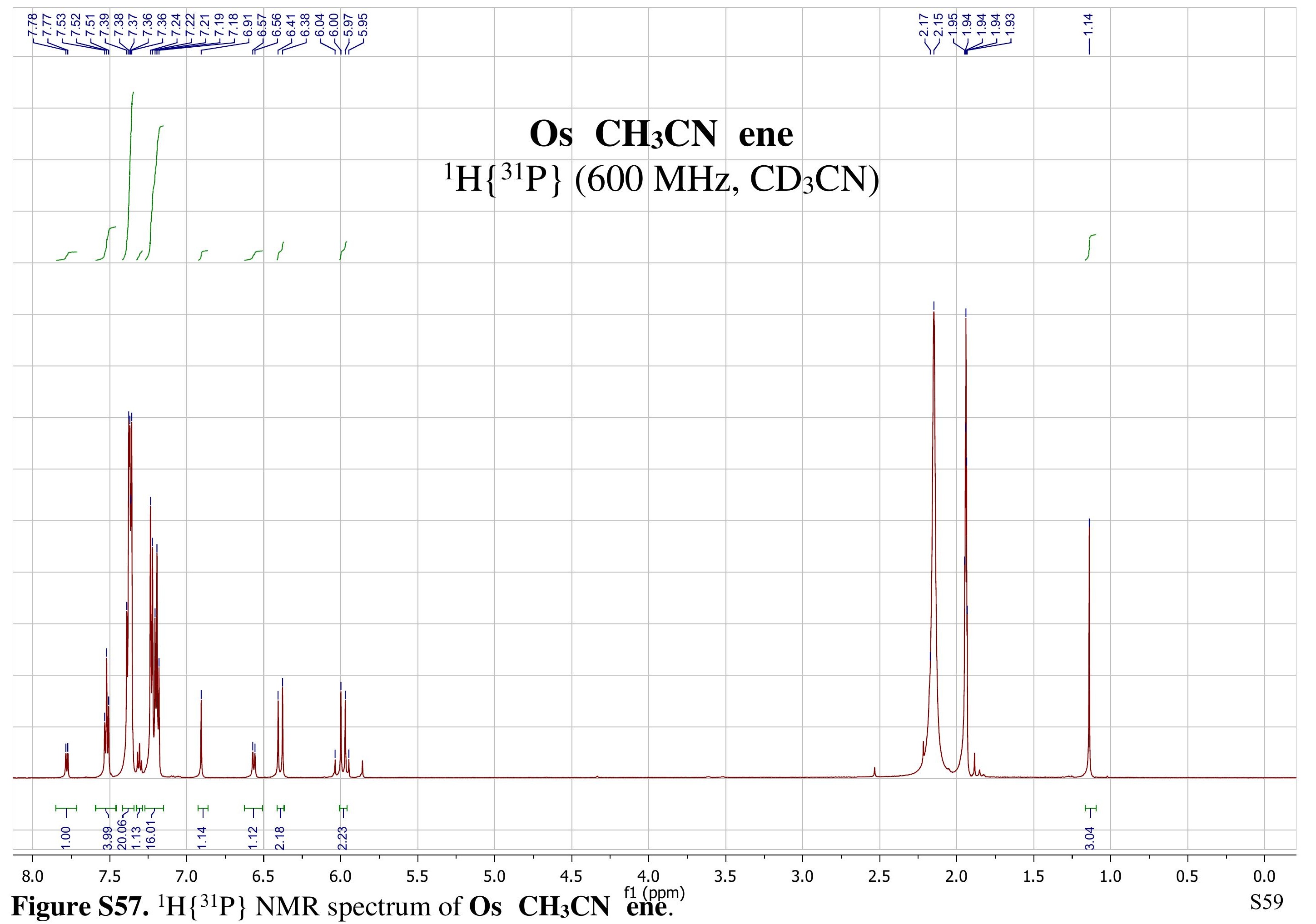




\section{Os $\mathrm{CH}_{3} \mathrm{CN}$ ene ${ }^{31} \mathrm{P}\left\{{ }^{1} \mathrm{H}\right\}\left(162 \mathrm{MHz}, \mathrm{CD}_{3} \mathrm{CN}\right)$}

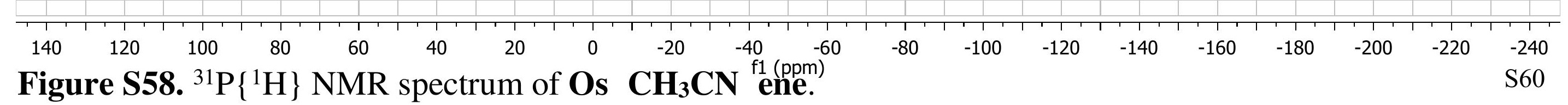




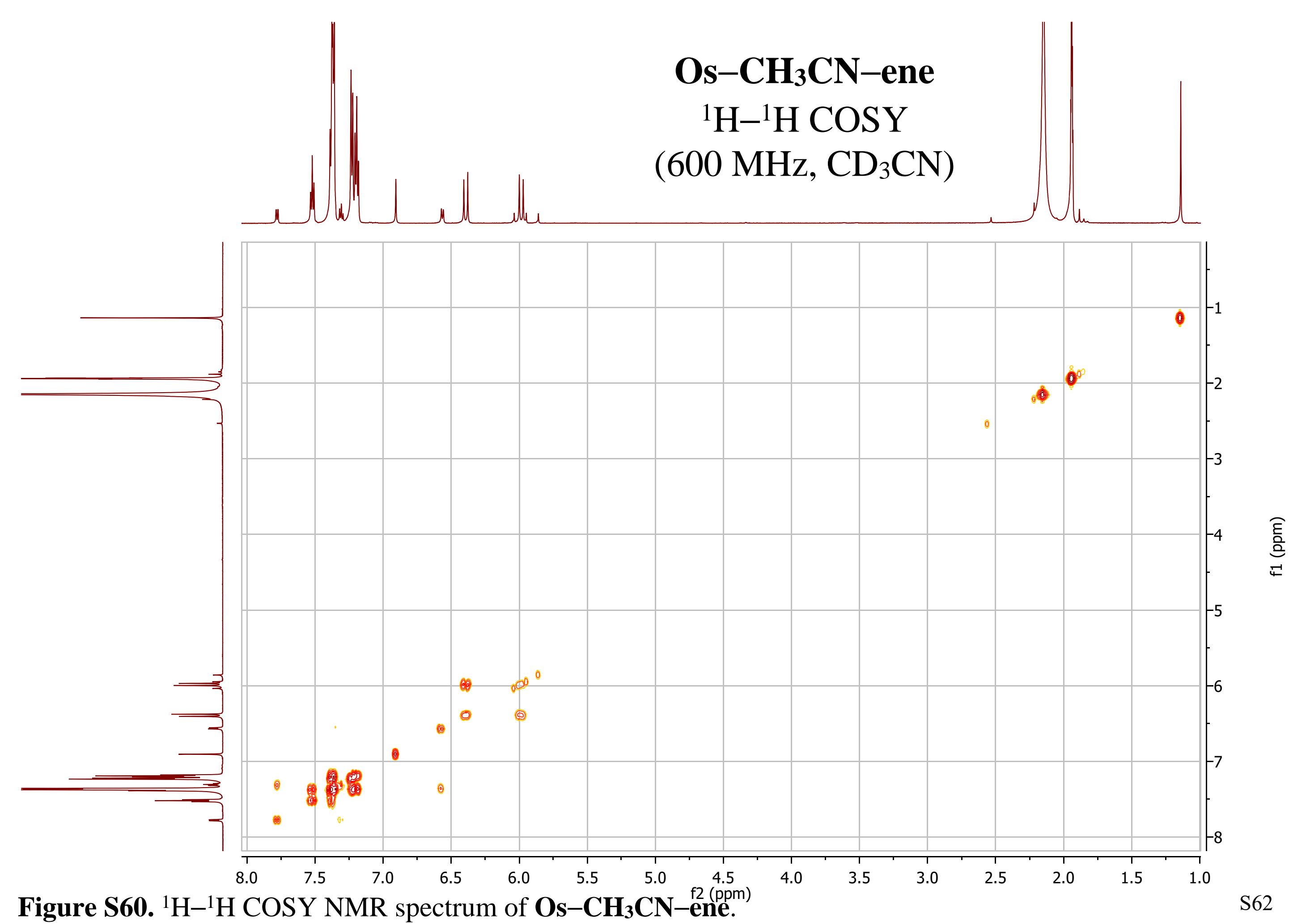




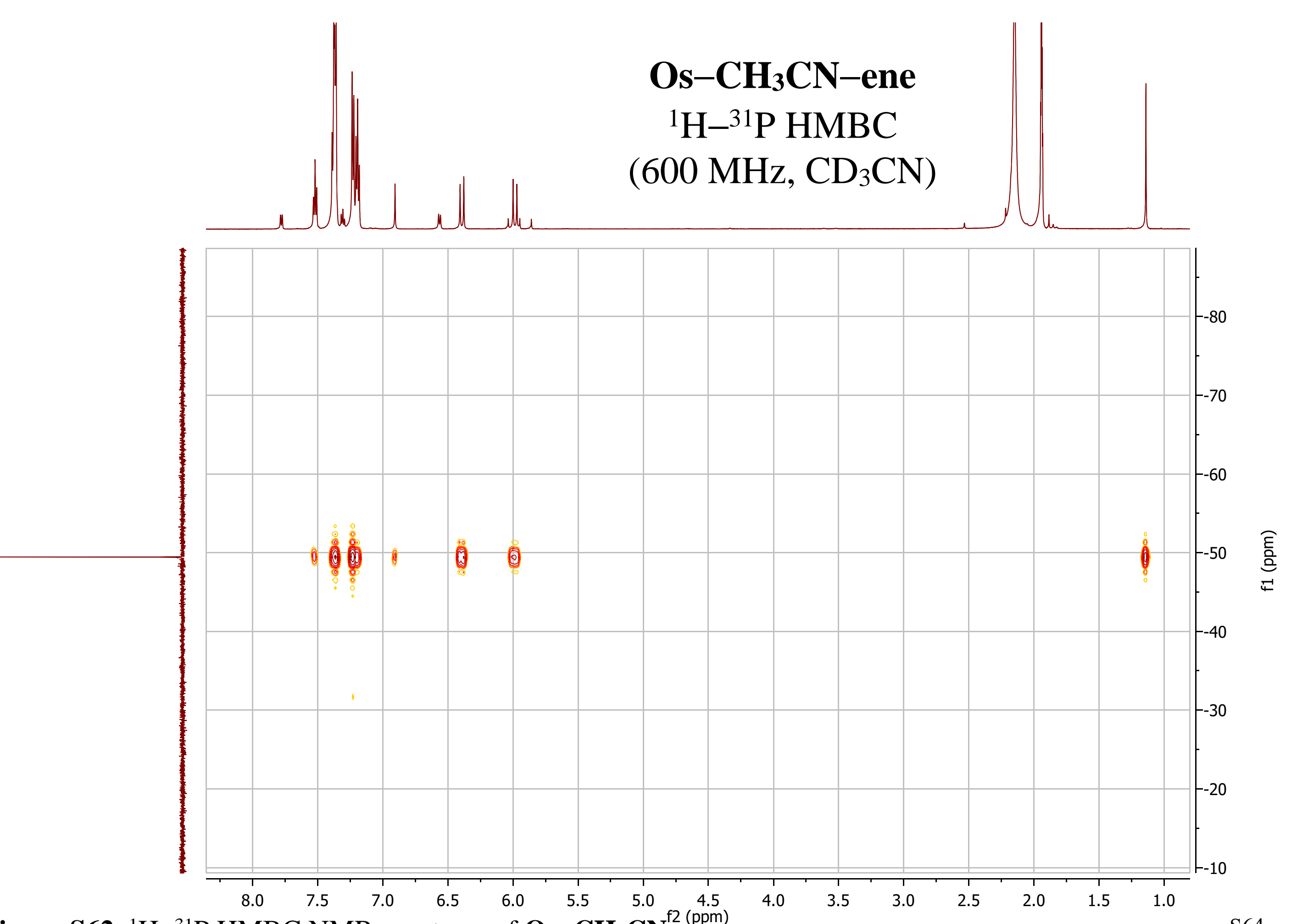

Figure S62. ${ }^{1} \mathrm{H}{ }^{31} \mathrm{P}$ HMBC NMR spectrum of $\mathbf{O s} \mathbf{C H}_{3} \mathbf{C N}^{\mathrm{f2}}$ ene. 


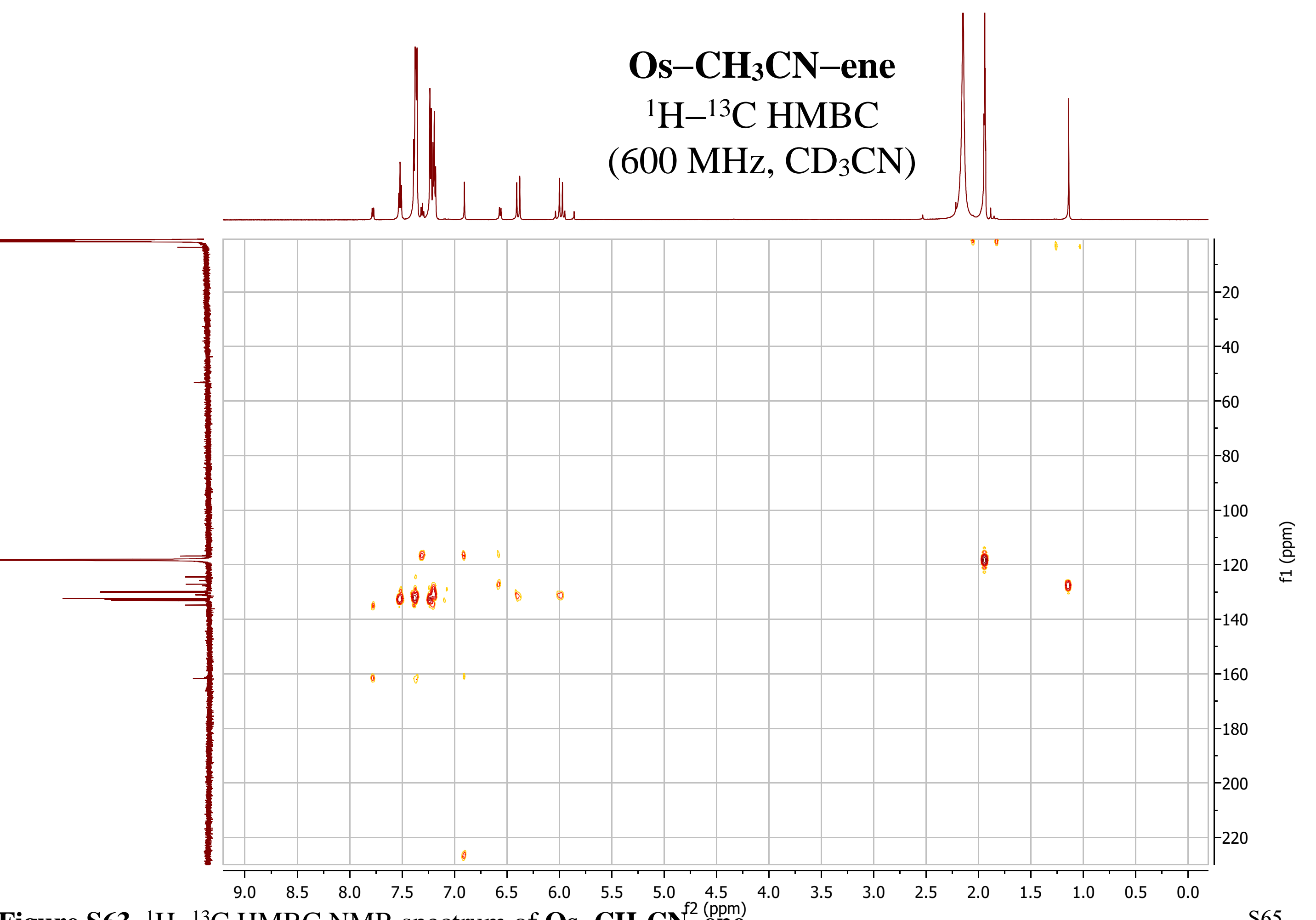

Figure S63. ${ }^{1} \mathrm{H} \quad{ }^{13} \mathrm{C}$ HMBC NMR spectrum of $\mathbf{O s} \mathbf{C H}_{3} \mathbf{C N} \mathbf{N}^{f(\text { epme }}$ ene. 


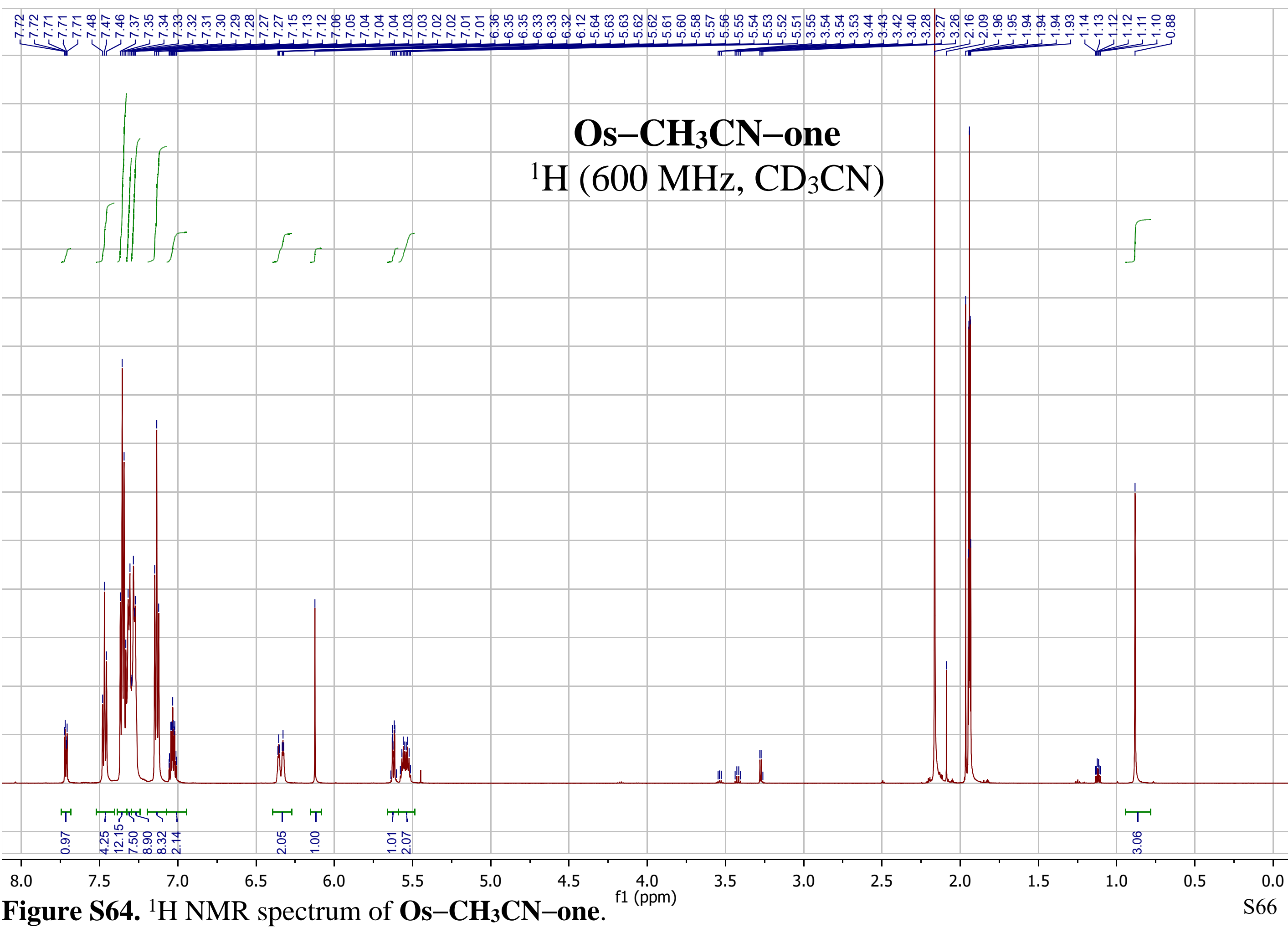




\section{Os $\mathrm{CH}_{3} \mathrm{CN}$ one} ${ }^{1} \mathrm{H}\left\{{ }^{31} \mathrm{P}\right\}\left(600 \mathrm{MHz}, \mathrm{CD}_{3} \mathrm{CN}\right)$
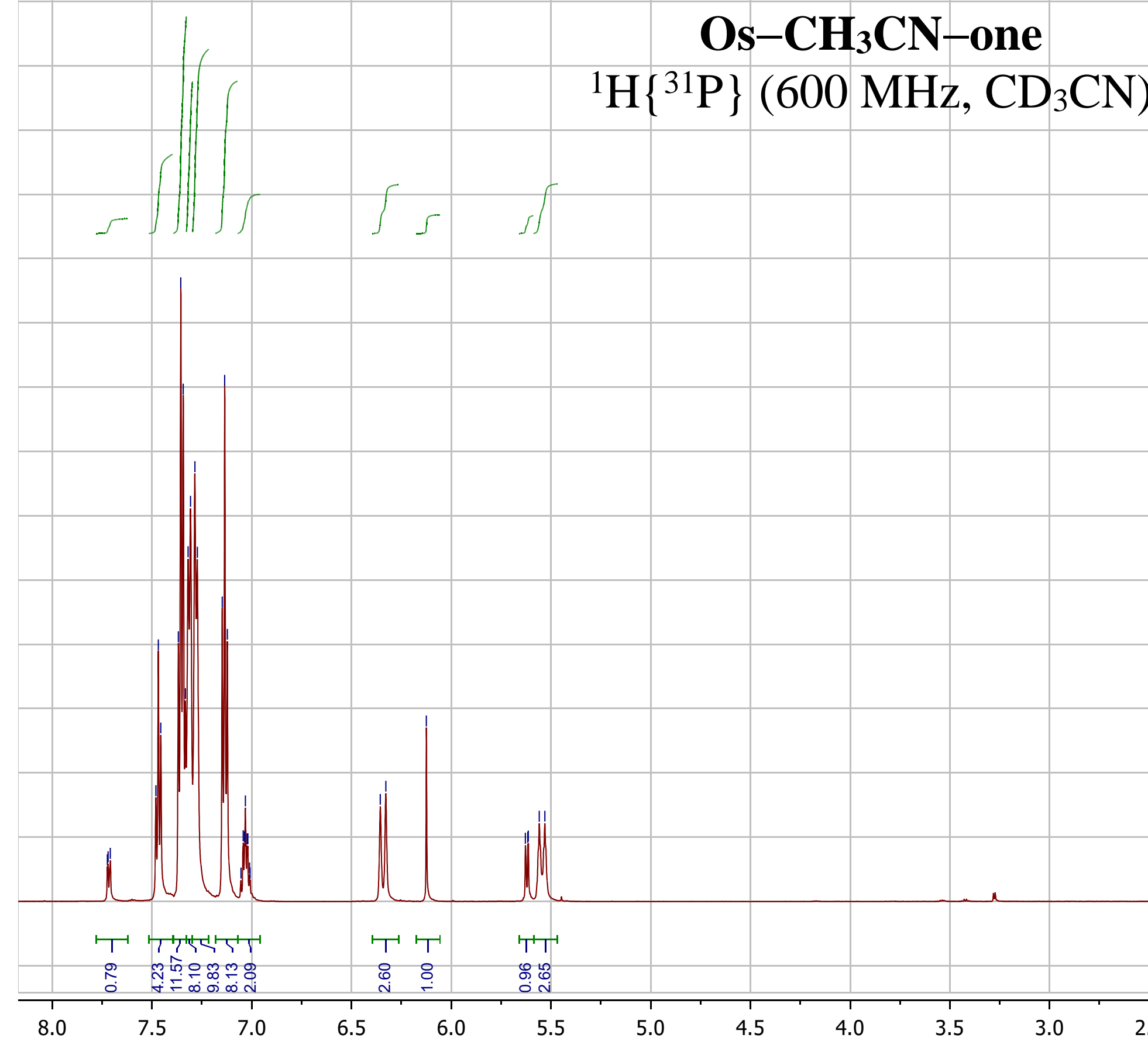

Figure S65. ${ }^{1} \mathrm{H}\left\{{ }^{31} \mathrm{P}\right\}$ NMR spectrum of $\mathbf{O s} \mathbf{C H}_{\mathbf{3}} \mathbf{C N} \stackrel{{ }^{1 f}(\mathrm{p} \text { )e })}{ }$

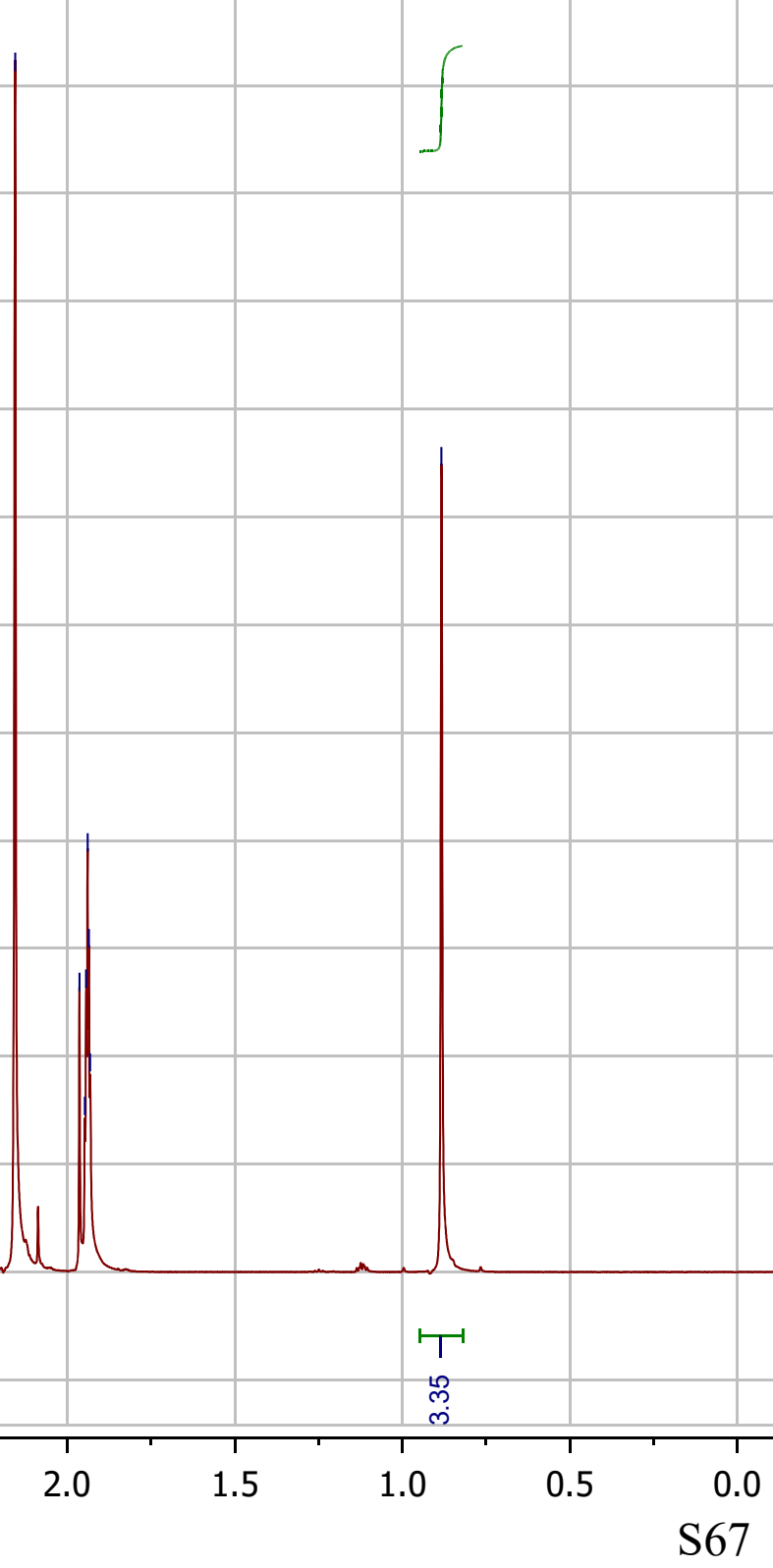




\section{Os $\mathrm{CH}_{3} \mathrm{CN}$ one ${ }^{31} \mathrm{P}\left(162 \mathrm{MHz}, \mathrm{CD}_{3} \mathrm{CN}\right)$}

$\begin{array}{lllllllllllll}70 & 60 & 50 & 40 & 30 & 20 & 10 & 0 & -10 & -20 & -30 & -40 & -50\end{array}$ $\mathrm{f}^{-50}(\mathrm{ppm})$

$\begin{array}{llll}-70 & -80 & -90 & -100\end{array}$

Figure S66. ${ }^{31} \mathrm{P}$ NMR spectrum of $\mathrm{Os} \mathrm{CH}_{3} \mathrm{CN}$ one. 


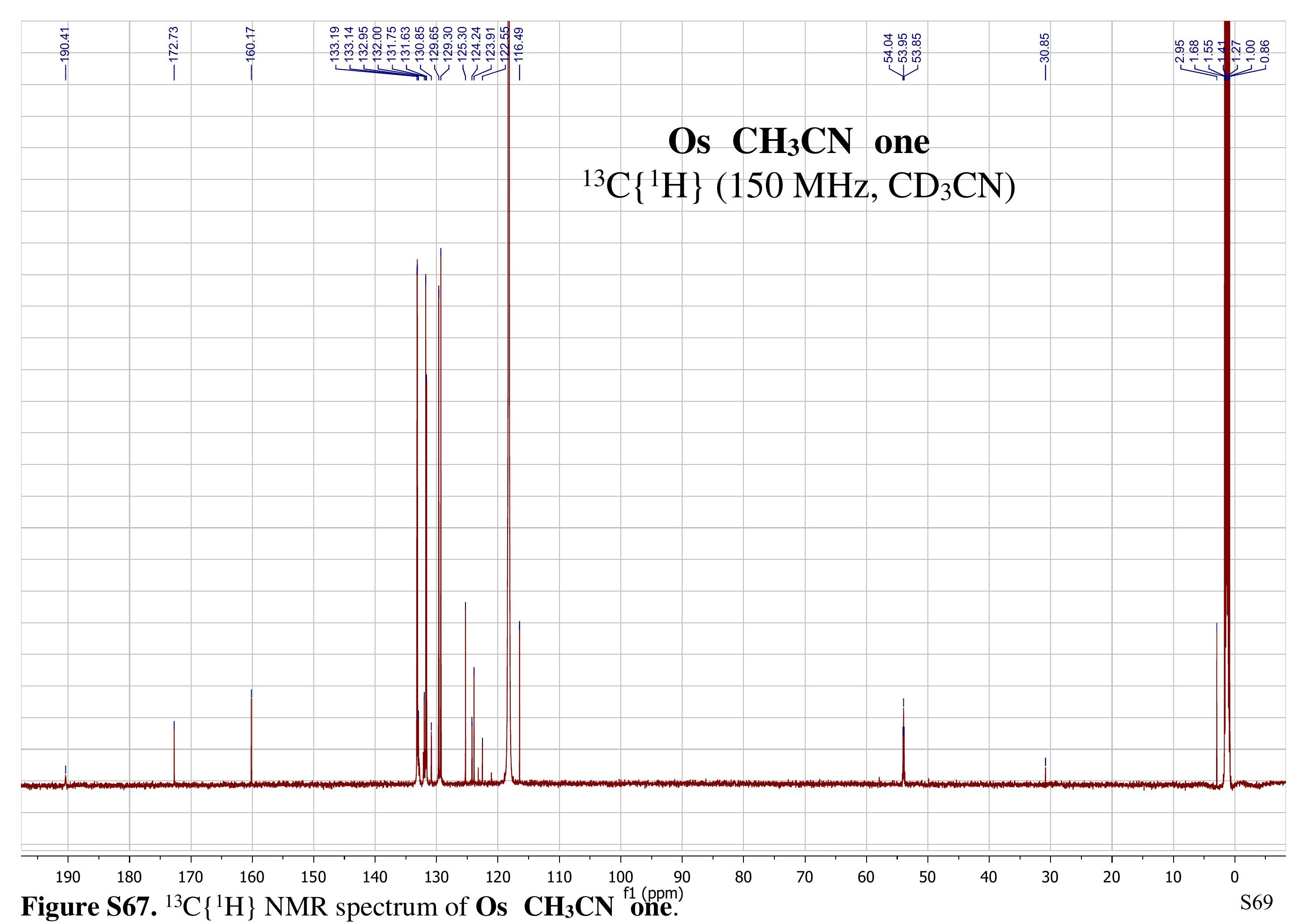




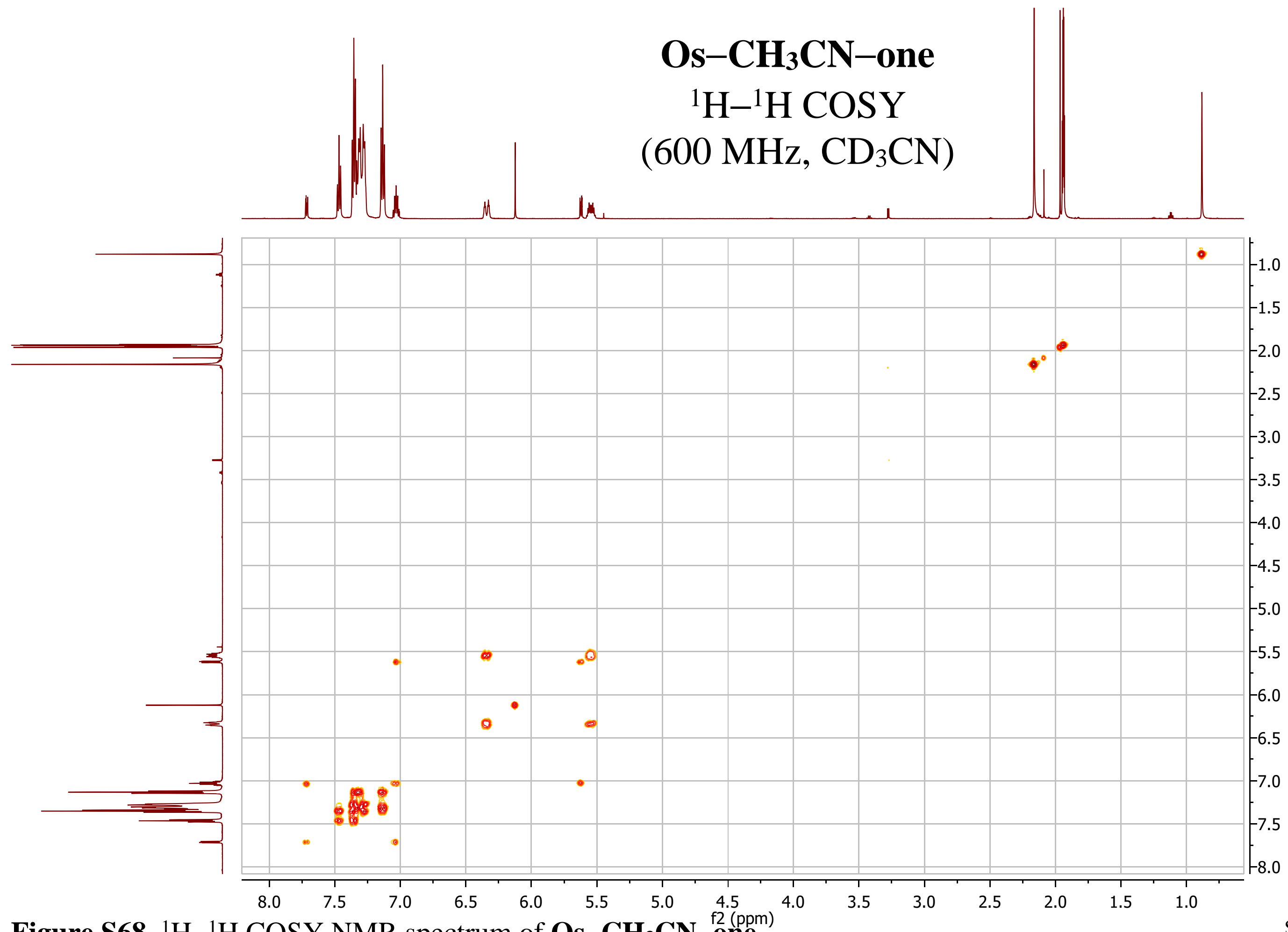

Os $\mathrm{CH}_{3} \mathrm{CN}$ one

${ }^{1} \mathrm{H}{ }^{1} \mathrm{H} \mathrm{COSY}$ $\left(600 \mathrm{MHz}, \mathrm{CD}_{3} \mathrm{CN}\right)$

Figure S68. ${ }^{1} \mathrm{H}{ }^{1} \mathrm{H}$ COSY NMR spectrum of $\mathbf{O s} \mathbf{C H}_{3} \mathbf{C N}{ }^{12}$ one. 


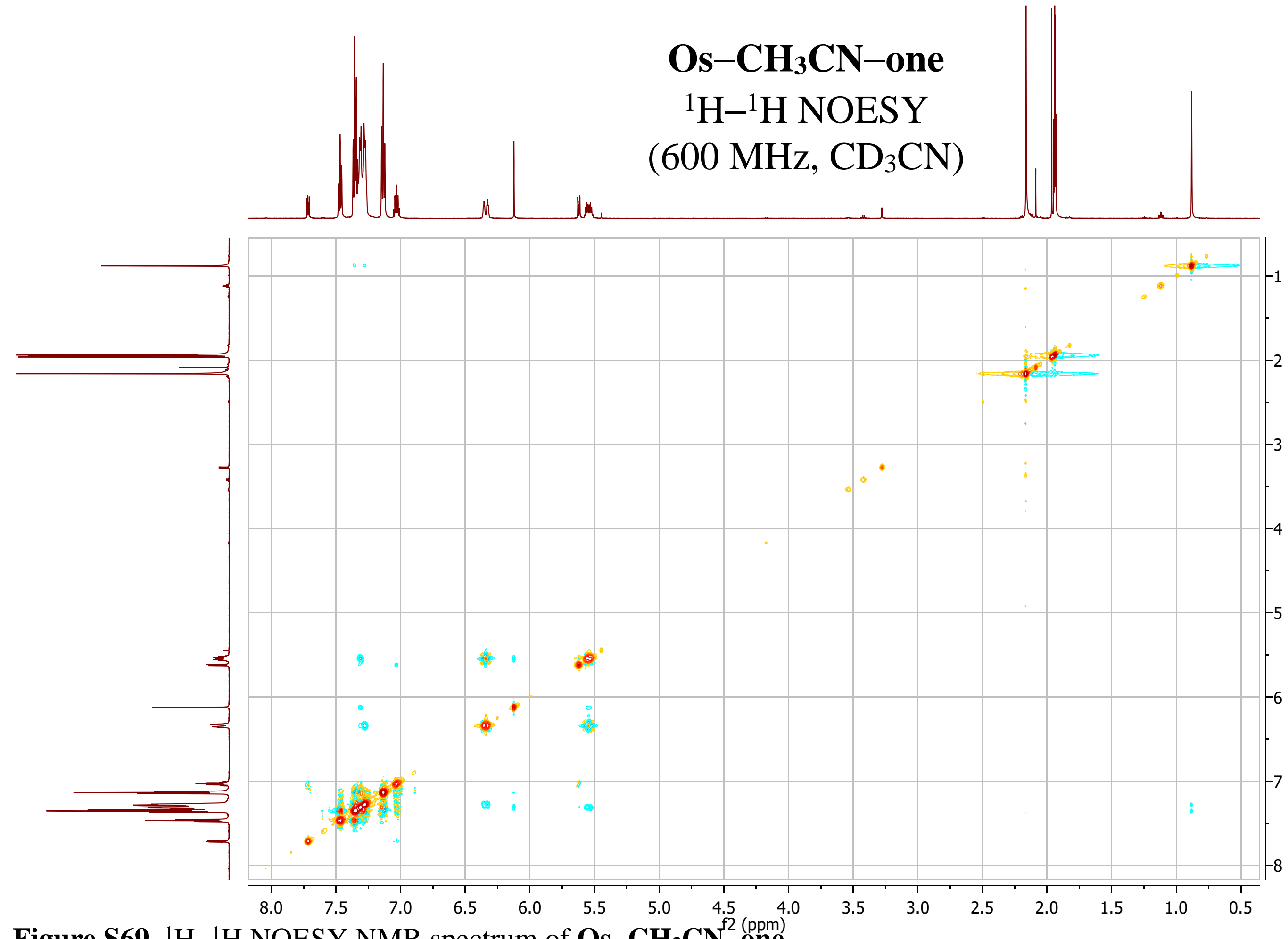

Os $\mathrm{CH}_{3} \mathrm{CN}$ one

${ }^{1} \mathrm{H}{ }^{1} \mathrm{H}$ NOESY $\left(600 \mathrm{MHz}, \mathrm{CD}_{3} \mathrm{CN}\right.$ )

Figure S69. ${ }^{1} \mathrm{H}{ }^{1} \mathrm{H}$ NOESY NMR spectrum of $\mathbf{O s} \mathbf{C H}_{3} \mathbf{C} \mathbf{N}^{22}$ one. 


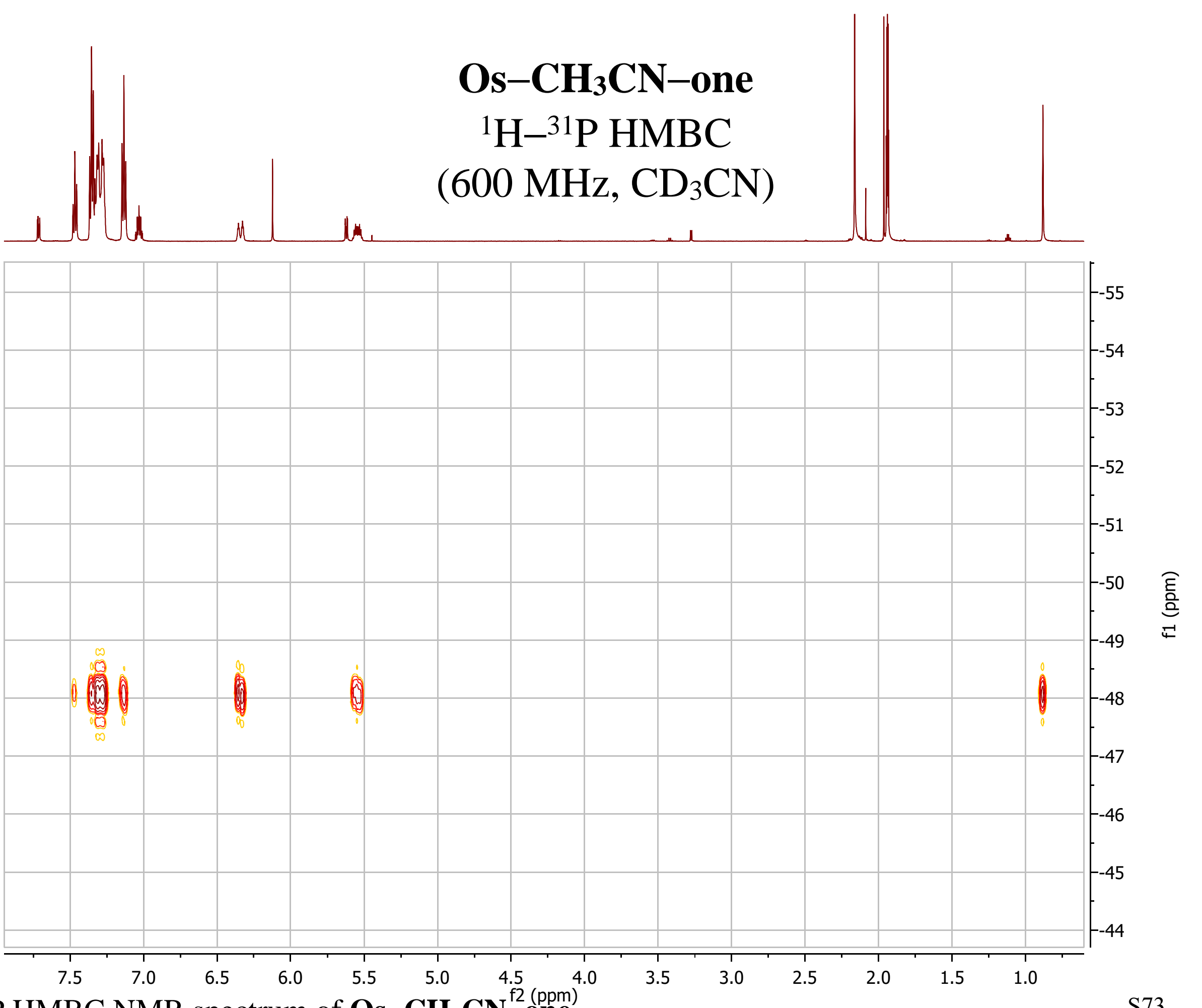

Figure S71. ${ }^{1} \mathrm{H} \quad{ }^{31} \mathrm{P}$ HMBC NMR spectrum of $\mathbf{O s} \mathbf{C H}_{3} \mathbf{C N}^{\mathrm{f2}}$ one. 


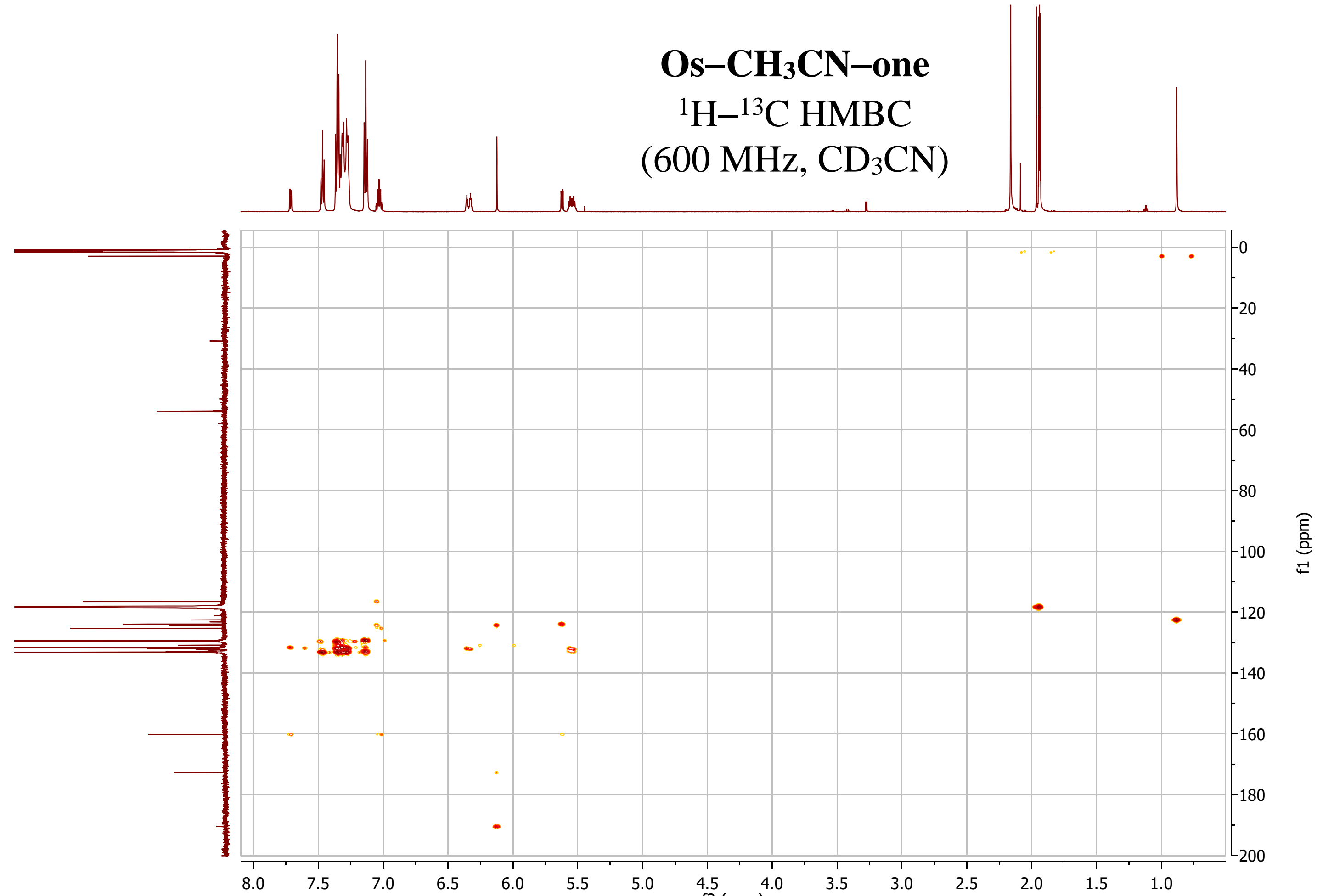

Figure S72. ${ }^{1} \mathrm{H}{ }^{13} \mathrm{C}$ HMBC NMR spectrum of $\mathbf{O s} \mathbf{C H}_{3} \mathbf{C N}^{f 2}(\mathrm{ppm})$ 


\section{References}

1. Neese, F. WIREs Comput. Mol. Sci. 2018, 8, e1327. 